\title{
Amygdalo-Entorhinal Relations and Their Reflection in the Hippocampal Formation: Generation of Sharp Sleep Potentials
}

\author{
Denis Paré, Jianming Dong, and Hélène Gaudreau \\ Départment de Physiologie, Faculté de Médecine, Université Laval, Québec, Canada G1K 7P4
}

While the anatomical relations between the amygdala, parahippocampal cortices, and hippocampus have been studied extensively, little is known about how they interact. To address this issue, we studied the timing of entorhinal (ENT), subicular, and basolateral amygdaloid (BL) discharges with respect to previously unknown population events, hereafter termed sharp potentials (SPs), that appear in the ENT cortex of cats during EEG-synchronized states.

SPs occurred in two forms. Simple SPs were monophasic potentials, negative in deep ENT layers and positive in layer I. Complex SPS appeared as simple SPs interrupted by a brief potential of opposite polarity. Simple SPs had no hippocampal correlate whereas complex SPs were followed by large potentials that could be recorded at several levels of the hippocampal loop under barbiturate anesthesia, but not beyond the dentate gyrus in natural sleep. In agreement with this, layer II ENT neurons and most subicular cells fired only in relation to complex SPs under anesthesia. Layer II ENT neurons fired in phase with SPs whereas subicular neurons fired $20-40 \mathrm{msec}$ later. In contrast, BL cells, layers IV-VI and layer III ENT neurons fired sequentially in relation to SPs with BL cells discharging as early as $\mathbf{4 0} \mathrm{msec}$ before SPs. Finally, amygdala lesions abolished ENT SPs.

These results suggest that the BL complex plays an essential role in the generation of population events that are transmitted to the ENT cortex. This is the first demonstration that spontaneous events occurring in the amygdala are reflected in the activity of related cortices. In turn, layer II ENT neurons gate the transfer of incoming inputs to the hippocampus. These findings shed light on the elaboration of normal and pathological activities in the amygdalo-hippocampal network.

[Key words: amygdala, entorhinal cortex, hippocampus, subiculum, perirhinal cortex, dentate gyrus, temporal lobe epilepsy]

\footnotetext{
Received June 22, 1994; revised Oct. 6, 1994; accepted Oct. 13, 1994.

I'his work was supported by MRC Grant MT-1 1562. We are deeply indebted to G. Oakson for writing the software used in the analysis. Thanks are also due to $M$. Steriade and D. Contreras for helpful comments on an earlier version of this manuscript as well ds to P. Giguère, D. Diolet, and I. Faure for technical assistance.

Correspondence should be addressed to Denis Paré, Département de Physiologic, Facultć de Mćdecine, Université Laval, Québec, Canada G1K 7P4. Copyright (C) 1995 Society for Neuroscience $0270-6474 / 95 / 152482-22 \$ 05.00 / 0$
}

The amygdaloid complex, parahippocampal cortices and hippocampal formation (dentate gyrus, CA fields, and subiculum) constitute a constellation of closely related structures that are believed to be implicated in various forms of learning (Lavond et al., 1993; Meunier et al., 1993; Squire et al., 1993; Suzuki et al., 1993; Zola-Morgan et al., 1993). A distinctive hodological feature common to these three structures is that they are endowed with prominent systems of intrinsic connections (Krettek and Price, 1978; Witter et al., 1986; Amaral and Witter, 1989). This characteristic is probably not coincidental to their hypothesized role in information storage, and may account for their low epileptogenic threshold (Liberson et al., 1951; Feindel and Penfield, 1954).

The entorhinal (ENT) cortex emerges as a nodal point in this system because it constitutes a bridge between the perirhinal cortex, main relay station of neocortical afferents to this part of the brain (Room and Groenewegen, 1986a), and the hippocampus (Witter and Groenewegen, 1984), that projects back to the ENT cortex (Room and Groenewegen, 1986a; Witter et al., 1989). As to the amygdaloid complex, it is reciprocally connected with several stations of this multisynaptic loop (Witter et al., 1989; Amaral et al., 1992) and contributes important glutamatergic projections (Paré and Smith, 1994; Smith and Paré, 1994) to the perirhinal and ENT cortices as well as to the subiculum (Krettek and Price, 1977a,b; Room and Groenewegen, 1986b).

While the profuse anatomical relations existing between these structures have been studied extensively, little is known about the influence they exert on each other. In particular, the relations between neuronal activities in the amygdaloid complex and related cortical projection fields have not been investigated so far. In the present study, we addressed this issue by investigating temporal relations between discharges of amygdaloid, ENT, and subicular neurons, with respect to large amplitude population events, hereafter termed sharp potentials (SPs), that occur spontaneously in the ENT cortex during natural slow-wave sleep and under barbiturate anesthesia. Tracking the sequence of events occurring in relation to these previously unknown ENT potentials simplified the study of neuronal interactions within this network.

In addition to providing the first description of ENT SPs, these experiments revealed that the BL amygdaloid nucleus generates population bursts that are transmitted to the ENT cortex. In turn, the ENT cortex acts as a gate controlling the transfer of incoming inputs to the hippocampal formation. These findings shed a new light on the organization principles determining the elabo- 
ration and distribution of normal and pathological activities in the amygdalo-hippocampal network.

A preliminary report of these results was presented elsewhere (Paré et al., 1994).

\section{Materials and Methods}

Acute experiments. This series of experiments was performed in cats $(2.5-3.5 \mathrm{~kg}$ ) anaesthetized with pentobarbital (Somnotol, $35 \mathrm{mg} / \mathrm{kg}$, i.p.; $n=23$ ) whose body temperature was maintained at $38^{\circ} \mathrm{C}$. In those experiments where single unit recordings were performed, the animals were paralyzed with gallamine triethiodide (Flaxedil, i.v.) and artificially ventilated (end-tidal concentration in $\mathrm{CO}_{2}$ was kept at $3.7 \pm$ $0.2 \%$ ). To ensure that the animals were anesthetized for the entire duration of the experiments, the EEG (recorded from the pericruciate region) was continuously monitored and supplementary doses of pentobarbital (5-7 mg/kg, i.v.) were administered to maintain a synchronized EEG pattern.

Unit discharges and related field potentials were recorded with tungsten microelectrodes (impedance $2-6 \mathrm{M} \Omega$ at $1 \mathrm{kHz}$ ) that were moved in $2-4 \mu \mathrm{m}$ steps by a piezoelectric micromanipulator. To physiologically identify ENT and subicular neurons, two arrays of five stimulating electrodes (intertip spacing of $1 \mathrm{~mm}$ ) were cemented together and were inserted in the hippocampal formation with an oblique, lateromedial approach so that one array was located in field CA1 and the other 0.5 $\mathrm{mm}$ deeper, in the molecular layer of the dentate gyrus (DG). In this position, these electrodes allowed stimulation $(0.05-0.2 \mathrm{msec}$ pulses of $0.01-0.2 \mathrm{~mA}$ ) of the mid septotemporal extent of the hippocampal formation. No attempts were made to formally distinguish neurons projecting to the DG or field CA1. The criteria used for antidromic identification included fixed response latency, collision with spontaneous or synaptically evoked action potentials, and ability to follow high-frequency stimulation $(>250 \mathrm{~Hz})$.

Recordings of hippocampal and ENT SPs were performed with pairs of tungsten microclectrodes (impedance 0.5-1 M $\Omega$ ) cemented to each other. The distance between the tips of these electrodes in the depth axis was $0.4-0.6 \mathrm{~mm}$ for hippocampal recordings and $1.0-1.3 \mathrm{~mm}$ for ENT recordings. These values, determined by performing laminar analyses of spontaneous and evoked activities, proved optimal to simultaneously monitor the sources and sinks related to SPs. These various signals $(0.1 \mathrm{~Hz}$ to $10 \mathrm{kHz})$ were observed on a digital oscilloscope, printed on a chart recorder, digitized, and stored on tape. Analyses were performed off-line with the software IGOR (Wavemetrics, Oregon) and home-made software running on Macintosh microcomputers.

Chronic experiments. These experiments were carried out in 3 cats weighing between 2.5 and $3.5 \mathrm{~kg}$. The initial implantation was performed under pentobarbital anesthesia (Somnotol, $35 \mathrm{mg} / \mathrm{kg}$ ). Two Teflon-insulated wires were inserted in the neck muscles to record electromyographic (EMG) activity and two silver-ball electrodes were cemented to the supraorbital cavity to record eye movements (EOG). The EEG was recorded by means of bipolar electrodes (tip-ring separation $0.8 \mathrm{~mm}$ ) cemented to the bone overlying the pericruciate region. Bipolar electrodes identical to those used in acute experiments were inserted bilaterally into the ENT cortex and cemented to the bone (see Results). The calvarium overlying the septal part of the hippocampus was removed and the exposed dura was covered with a polystyrene cylinder. The animals were implanted in a stereotaxic position with four screws protruding from the dental cement. These screws were later used to fix the cat's head to the stereotaxic apparatus without pain or pressure. Bicillin and the analgesic Torbusegic were administered postoperatively for $2 \mathrm{~d}$. The recording sessions began 7-9 d after the surgery. The animals slept ad libitum between the recording sessions.

EEG, EOG, and EMG signals were used to identify behavioral states. See Steriade and Hobson (1976) for a detailed account of the electrographic criteria used to distinguish behavioral states of vigilance. The EEG signals recorded from the pericruciate region, ENT corlex, and hippocampus as well as the EOG and EMG potentials were printed on a chart recorder, digitized, and stored on magnetic tape.

Excitotoxic and electrolytic lesions. To verify if $\mathrm{ENI} \mathrm{SP}$ are generated in, or mediated by, the amygdaloid complex, excitotoxic or electrolytic lesions were placed in and around the amygdala. Excitotoxic lesions were made by performing several (four to eight) microinjections $(0.002-0.01 \mu \mathrm{l})$ of kainic acid (1\% in $0.9 \%$ saline) stereotaxically directed to or in the vicinity of the amygdaloid complex. Electrolytic lesions $(1 \mathrm{~mA}$ for $10 \mathrm{sec})$ were made with tungsten microelectrodes.
Identification of the recording sites. The stereotaxic coordinates of deeply lying structures were derived from the atlas of Berman and Jones (1982). However, it became clear that the dorsoventral position of the ENT cortex varied from one animal to the next. To solve this problem, the electrodes aimed at the ENT cortex for field potential recordings were slowly lowered until they touched the temporal bone and then retracted to the desired position. These electrodes were then used to physiologically identify hippocampal recording sites in accordance with conventional electrophysiological criteria (Andersen et al., 1966a, 1966b; Van Groen and Lopes Da Silva, 1985; Paré et al., 1992).

Before retracting stimulating and recording electrodes, the location of their tip and/or their trajectory were routinely marked by two or more small electrolytic lesions $(0.5 \mathrm{~mA}$ for $2-5 \mathrm{sec})$. To avoid confusion between different electrode tracks, no more than three tracks were performed in a given structure and the distance between the lesions marking each track was varied systematically. At the end of the experiments, the brains were perfused with $500 \mathrm{ml}$ of a cold saline solution $(0.9 \%)$ followed by 1 liter of a fixative containing $2 \%$ paraformaldehyde and $1 \%$ glutaraldehyde in $0.1 \mathrm{M}$ phosphate buffer saline ( $\mathrm{pH}$ 7.4). The brains were then stored for $24 \mathrm{hr}$ in a $30 \%$ glucose solution, sectioned on a freezing microtome (at $80 \mu \mathrm{m}$ ), and stained with thionin to verify the position of the recording electrodes. The microelectrode tracks were reconstructed by combining micrometer readings with the histological controls.

\section{Results}

\section{Description of ENT SPS}

Because most of the connections between the amygdaloid complex and hippocampus are relayed by the ENT cortex, the starting point of this investigation was to characterize ENT SPs. To this end, bipolar electrodes (see Materials and Methods) were positioned in the ENT cortex so that one recording lead was located close to the base of the skull, in layer I, and the other $1.0-1.3 \mathrm{~mm}$ above, in layers IV-VI. Using this approach, SPs occurring at an average frequency of $2-3 \mathrm{~Hz}$ could be recorded bipolarly from most sectors of the ENT cortex (ventrolateral, ventromedial, medial) of barbiturate-anesthetized (Fig. 1) and naturally sleeping (see Fig. 4) cats.

In barbiturate-anesthetized cats, ENT SPs appeared as 0.1$1.2 \mathrm{mV}$ potentials that stood out on an otherwise flat EEG background. However, in some cats they were intermixed with short trains $(0.5-1.5 \mathrm{sec})$ of $15-16 \mathrm{~Hz}$ waves recurring every $2-3 \mathrm{sec}$ (Fig. 1A). In naturally sleeping cats, ENT SPs were most frequent in deep slow wave sleep when the neocortical EEG displayed large amplitude delta waves. During this state, they occurred in isolation or in groups of two to four (at a frequency of $1.5-2.5 \mathrm{~Hz}$ ) and their amplitude could reach up to $1.5 \mathrm{mV}$. ENT SPs also occurred during drowsiness, but they were less frequent and of smaller amplitude. They never occurred in the waking state or during the paradoxical phase of sleep.

In barbiturate-anesthetized and naturally sleeping cats, two types of ENT SPs were distinguished. Simple SPS (Fig. 1C) appeared as 50-100 msec monophasic potentials that were positive in layer I and negative in deeper layers. In some experiments, they were followed hy a slower (up to $0.3 \mathrm{sec}$ ) potential of opposite polarity (Fig. $2 A$ ). In contrast, complex SPs (Fig. $1 D$ ) were polyphasic potentials of larger amplitude. In layer I, they appeared as positive waves interrupted by a brief $(20-40$ $\mathrm{msec}$ ) negative potential hereafter referred to as the spike component (arrow in Fig. 1D2, top trace). In deep layers, the same sequence of potentials was observed but reversed in polarity. Simple and complex SPs had a similar appearance in naturally sleeping and barbiturate-anesthetized cats with the exception that they lasted longer in chronic cats $(50-150 \mathrm{msec}$ in acute cats compared to $150-200 \mathrm{msec}$ in chronic cats). 
Figure 1. ENT SPs in barbiturateanesthetized cats. Ventrolateral ENT area. (A) Monopolar recordings obtained from the surface (Surf., layer I) and depth (layers IV-VI). The underlined period in $A$ is shown with a faster time base in $B$ along with a bipolar ( $B i$ $\mathrm{pol}$.) trace. In this and following figures, bipolar ENT recordings were obtained by subtracting the superficial signal from the depth signal. $C$ and $D$ show superimposed simple $(C)$ and complex $(D)$ SPs using the negative peak of the bipolar signal as a temporal reference. $D 2$ depicts the average of the traces shown in D1. Arrows point to the spike component of complex ENT SPs.
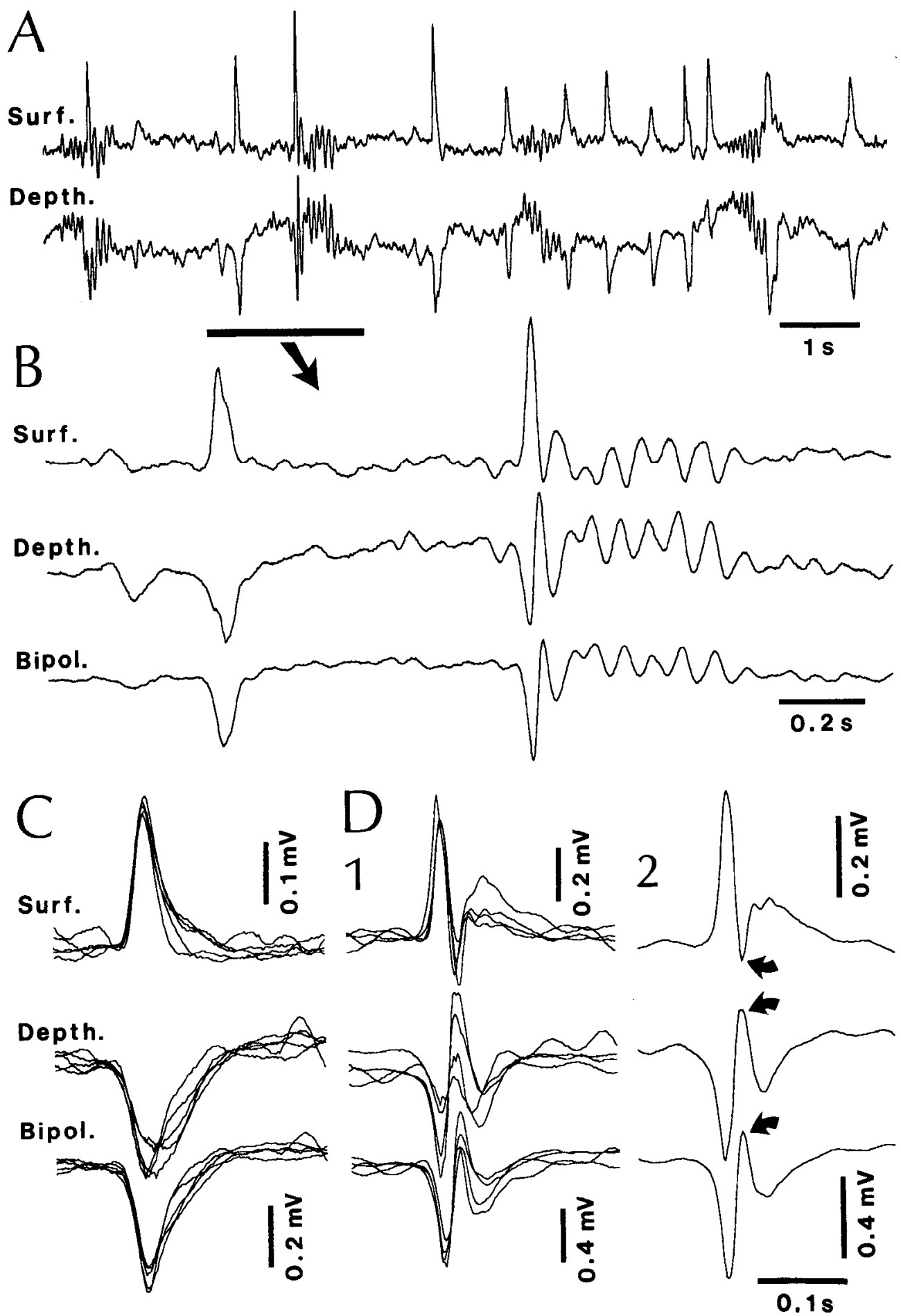

The proportion of complex to simple SPs changed with the depth of anesthesia. At deep levels of anesthesia, when the first signs of the burst-suppression EEG pattern were apparent (Derbyshire et al., 1936), only simple SPs occurred. These SPs usually were of a higher amplitude than those seen at lower levels of anesthesia. As the depth of the anesthesia was allowed to decrease, the frequency of SPs remained unchanged but the proportion of complex SPs increased. At such levels of anesthesia, the neocortical EEG was still dominated by large-amplitude spindles and, in unparalyzed cats, reflexes had not returned. Most complex SPs observed in this condition were preceded by a small amplitude simple SP that occurred 80-140 msec before the peak of these complex SPs (see Figs. 10, 11). Because this interval is much shorter than that normally separating simple SPs (250-500 msec), this phenomenon gave the impression that the ENT network had to be primed by a low-intensity afferent volley to generate complex SPs.

Finally, in barbiturate anesthetized cats, ENT SPs could be evoked by sensory stimuli but they habituated rapidly. Any intense sensory stimuli (visual, auditory, and somesthesic modalities) could evoke SPs provided that the same sensory stimuli was not repeated more than a few times (not shown). 


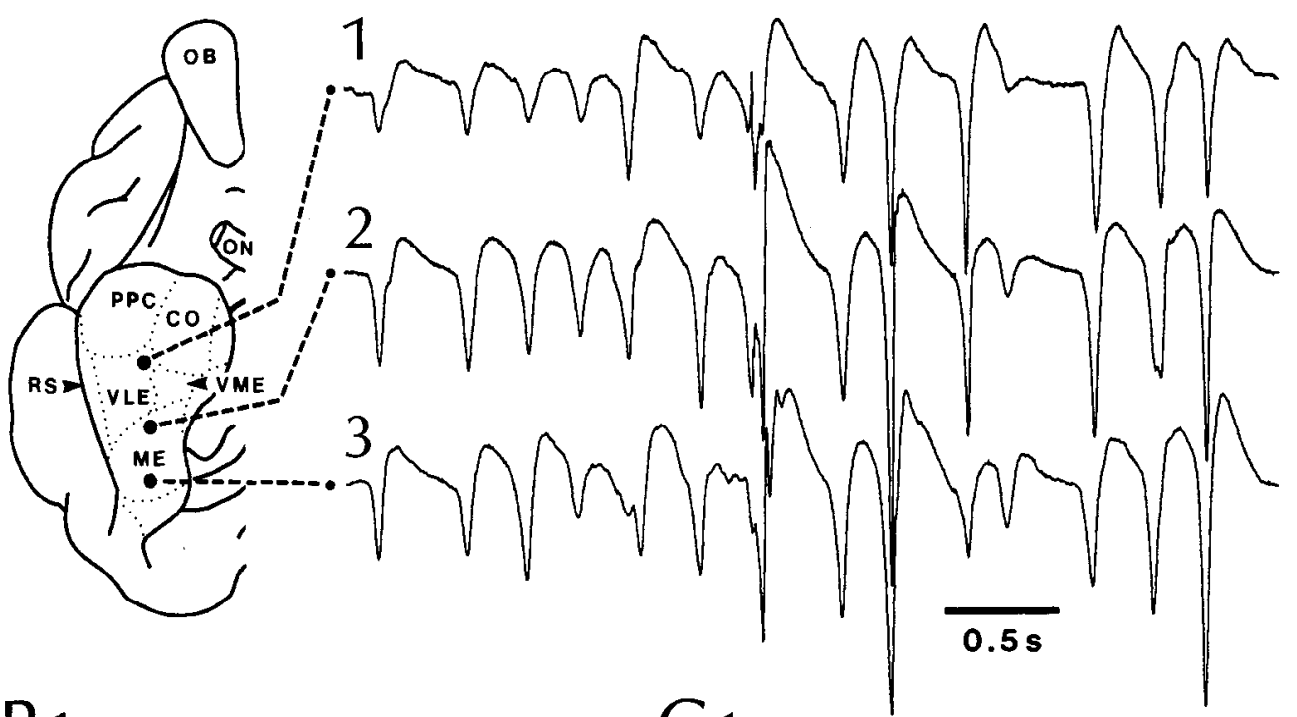

B1

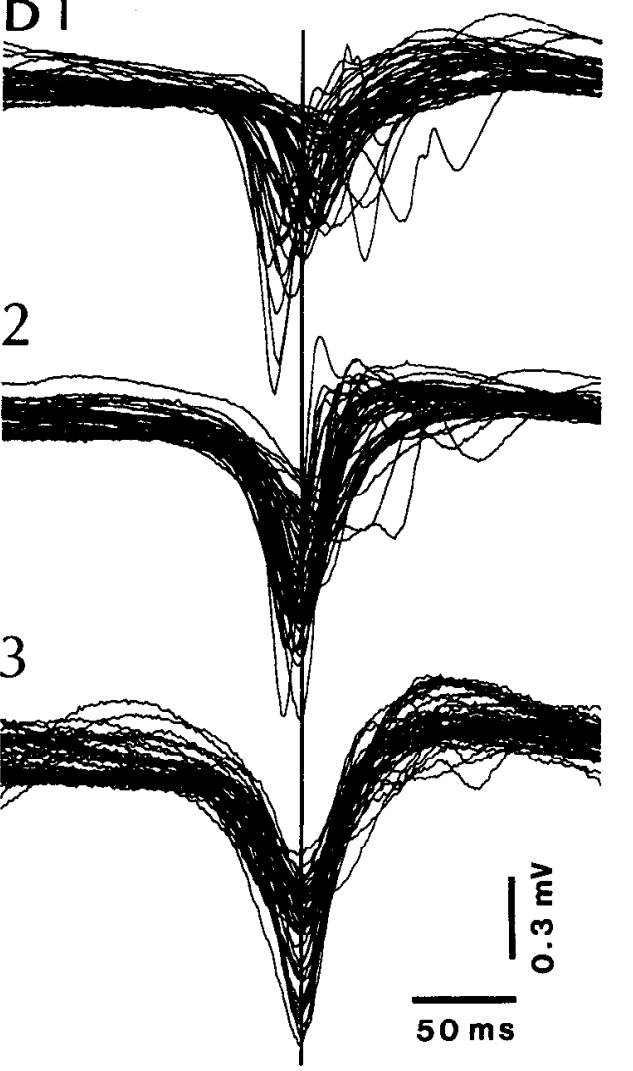

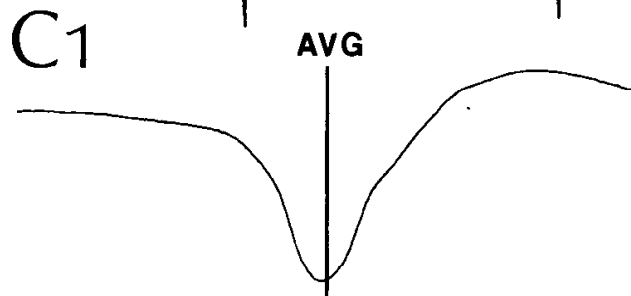

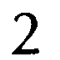

3
Synchrony of SPs in the ENT cortex

Multiple bipolar recordings of ENT SPs were performed under barbiturate anesthesia to determine if the activity of different ENT sectors is synchronized $(n=3)$. A representative example of such an experiment is shown in Figure 2, where three bipolar electrodes were inserted at different rostrocaudal levels of the ventrolateral and medial ENT areas (see scheme on the left of Fig. $2 A$ for the electrode configuration). In this and following figures, the subtraction between superficial and deep ENT signals was performed so that the polarity of bipolar ENT SPs was the same as those recorded monopolarly from deep ENT layers.
SPs appeared synchronously in different ENT sectors (within $10 \mathrm{msec}$ of each other). It was exceptional that SPs occurred only in one of the recording sites. However, the dispersion of SPs in time increased with distance from the ENT electrode used as a temporal reference. This is shown in Figure $2 B$, where 40 SPs were superimposed using the peak of ENT SPs recorded by the most caudal electrode as a temporal reference (Fig. 2B3). Note that the temporal dispersion of SPs increases with distance from the reference electrode (compare Fig. 2B2,BI). Yet, the peak of averaged SPS recorded at these three ENT sites were within 4 msec of each other. 


\section{Relation between ENT SPs and hippocampal activities}

Anesthetized cats. To determine the relation between ENT SPs and hippocampal activities, simultaneous CA1 and ENT field potential recordings were performed $(n=7)$. First, a laminar analysis of ENT-evoked hippocampal responses and spontaneous events was carried out to determine the location of the pyramidal and granule cell layers. Then, the bipolar electrode was retracted until the deep and superficial leads reached stratum radiatum and stratum oriens, respectively. Finally, ENT and related CA1 events were recorded bipolarly at different levels of anesthesia. At the end of these experiments, two electrolytic lesions were made: one in the pyramidal layer and another $1 \mathrm{~mm}$ below (Fig. 3A). The physiologically determined position of the two leads in stratum oriens and stratum radiatum (black dots in Fig. $3 A$ ) was confirmed by combining the micrometer readings and the corresponding histological control.

Under these conditions, CAl recordings were characterized by the occurrence of large amplitude, short-lasting potentials (hereafter termed CA1 SPs) that were negative in stratum radiatum and positive in stratum oriens. In stratum radiatum, hippocampal SPs appeared as 30-60 msec negative potentials $(0.2-2$ $\mathrm{mV}$ ) that were followed by a slower (100-300 msec) positive wave. The same sequence of potentials was observed in stratum oriens, but they were of smaller amplitude $(30-300 \mu \mathrm{V})$ and reversed polarity. Laminar analyses revealed that CA1 SPs and ENT-evoked CAl responses reversed in polarity immediately below the pyramidal layer. Figure $3 B$ compares the average of ten ENT-evoked responses (Fig. 3Bl) and hippocampal SPs (Fig. 3B2). Note the similar time course and polarity of these averaged potentials in stratum oriens (or) and radiatum (rad).

The frequency and amplitude of CA1 SPs varied with the depth of the anesthesia. In Figure $3 C$, simultaneous bipolar recordings of ENT and CA1 SPs are depicted, before (Fig. 3C1) and after (Fig. 3C2) the administration of pentobarbital (Somnotol, $5 \mathrm{mg} / \mathrm{kg}$, i.p.). Following barbiturate administration, the overall frequency of hippocampal SPs gradually decreased from approximately $2-0.7 \mathrm{~Hz}$. In contrast, the frequency of ENT SPs remained roughly the same while their amplitude increased. At deeper levels of anesthesia, when only simple ENT SPs occurred, CAl SPs were abolished.

To determine the temporal relation between ENT and hippocampal SPs, 50 ENT SPs were averaged using the peak of CA1 SPs as a temporal reference. The shape of the resulting potential corresponded to that of a complex ENT SP $(n=7)$. A representative example of this is shown in Figure $3 \mathrm{DI}$. Note that the negative peak of the complex ENT SP occurs $27 \mathrm{msec}$ before that of the CA1 SP (range $25-30 \mathrm{msec}, n=7$ ), a delay similar to the latency to peak of ENT-evoked responses (Fig. $3 B 1$ ). In addition, the averaged ENT SP clearly begins before the averaged CAI SP, thus suggesting that CAl SPs represent a synaptic response to a synchronized ENT input.

To determine if simple and complex ENT SPs are differen- tially related to CA1 SPs, 50 hippocampal SPs were averaged using the negative peak of complex (Fig. 3D2) or simple ENT SPs (Fig. 3D3) as a temporal reference $(n=3)$. The amplitude of the avcraged CA1 SP was much higher when complex ENT SPs were used as a reference (compare Fig. 3D2,D3). This differential relation between simple and complex SPs with respect to CA1 SPs suggests that complex ENT SPs are correlated to the discharge of ENT neurons with hippocampal projections whereas simple ENT SPs are not.

Naturally sleeping cats. The relation between ENT and hippocampal SPs was sludied in three chronically implanted cats (Fig. 4). As was observed in anesthetized cats, simple SPs had no correlate in the hippocampal formation. However, it was found that complex ENT SPs reliably precede sharp negative potentials whose amplitude is maximal in the molecular layer of the DG and whose polarity reversed around the granule layer. Figure 4 illustrates simultaneously recorded ENT and dentate SPs. Note that superimposed on dentate SPs were fast oscillations at $40-120 \mathrm{~Hz}$ (Fig. $4 B, E$ ). When dentate SPs were averaged using the negative peak of complex ENT SPs as a temporal reference, it was found that the peak of dentate SPs occurred 17 to $23 \mathrm{msec}$ after that of ENT SPs ( $22 \mathrm{msec}$ in Fig. 4C,D; $n=$ 3 ). In contrast with barbiturate anesthetized cats, ENT SPs had no reflection in the hippocampal formation beyond the DG and appeared unrelated to hippocampal sharp waves (Buzsaki, 1986; Suzuki and Smith, 1987) since ENT SPs and hippocampal sharp waves were usually separated by an interval of $300 \mathrm{msec}$ or more.

\section{Laminar analyses of simple and complex ENT SPS}

Laminar analyses of simple and complex ENT SPs were performed with a moving tungsten electrode lowered approximately $1.5 \mathrm{~mm}$ rostral to a fixed bipolar electrode located in the ENT cortex $(n=5)$. Using the peak of bipolarly-recorded ENT SPS as a temporal reference, 15-20 ENT SPs recorded with the moving electrode were averaged cvery $100 \mu \mathrm{m}$ across the depth of the medial $(n=3)$ or lateral $(n=2)$ sectors of the ENT cortex. The laminar profiles of SPs in these two ENT sectors was identical. As shown in Figure 5, the polarity of all components of simple and complex SPs reversed in or close to layer II (arrowhead pointing to electrolytic lesion). Another consistent observation was a gradual temporal shift of the negative peak of simple and complex SPs across the depth of the ENT cortex. Indeed, the negative peak of SPs occurred earlier in deep ENT layers and progressively later as the electrode approached superficial ENT layers or, in the dorsal direction, the subiculum.

\section{Extracellular recording of neuronal activity related to SPS}

In order to determine the nature of the sinks and sources evidenced in the laminar analyses of ENT SPs and identify the sequence of events that contribute to the genesis and propagation of these potentials in the amygdalo-hippocampal network, extra-

\footnotetext{
Figure 3. Simultaneous recording of hippocampal and ENT SPs in barbiturate-anesthetized cats. $(A)$, Histological control. Dashed lines indicate

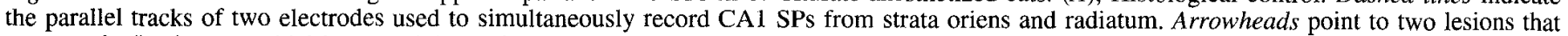

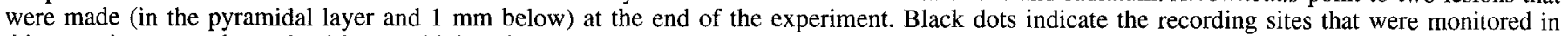

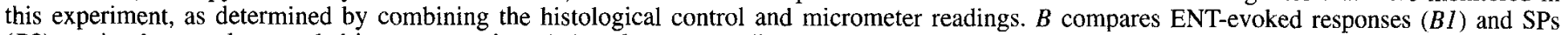

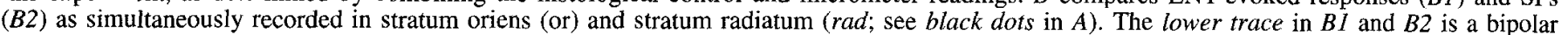
recording obtained by subtracting the superficial (or) from the deep ( rad) signals. $C$ shows simultaneous bipolar recordings of ENT and CA1 SPs before $(C I)$ and after $(C 2)$ the administration of sodium pentobarbital (Somnotol, $5 \mathrm{mg} / \mathrm{kg}$, i.p.). $D$, averages of C.A1 and ENT SPs using as a temporal reference the peak of (1) CAl SPs, (2) complex ENT SPs, or (3) simple ENT SPs (see text).
} 

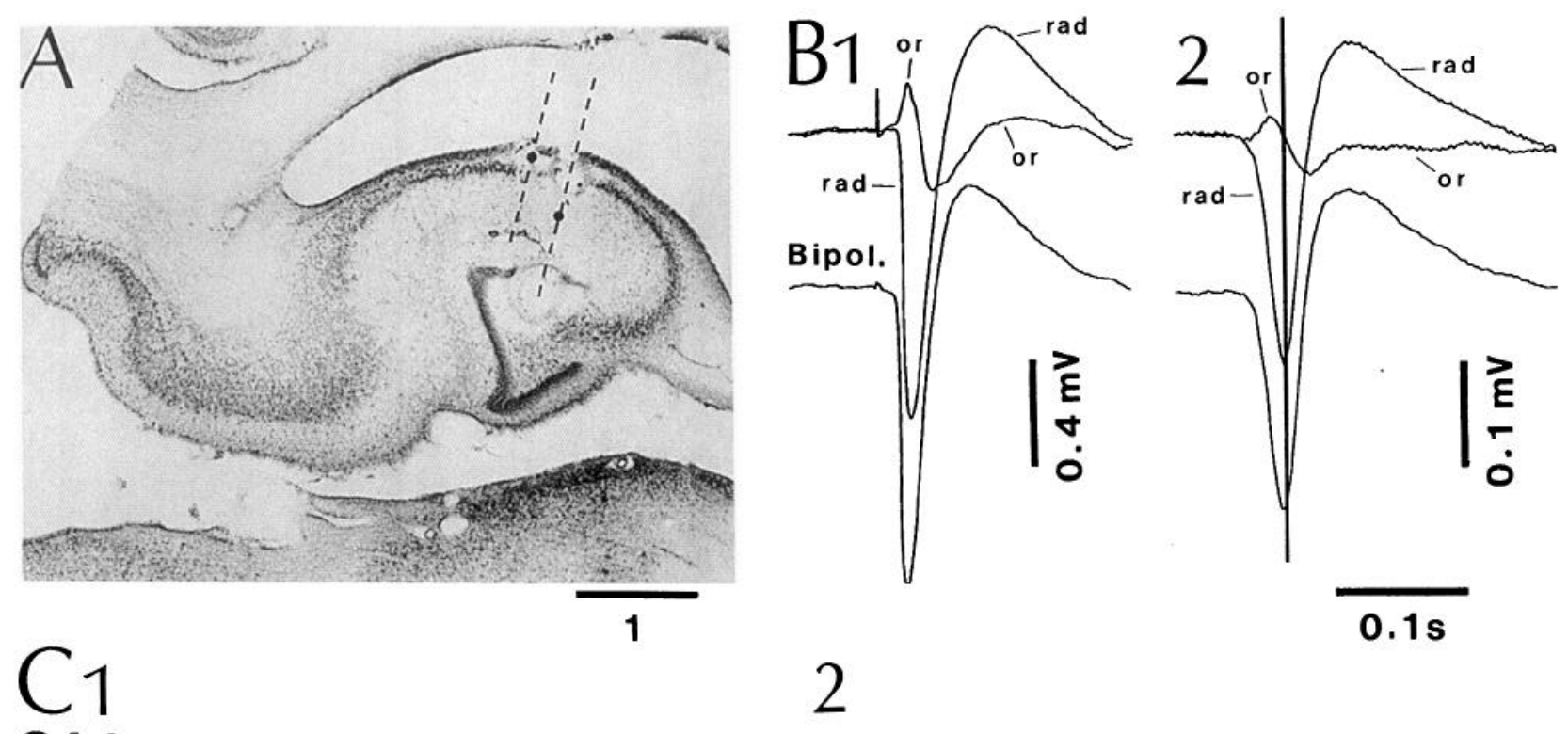

2

CA1-Bipol.

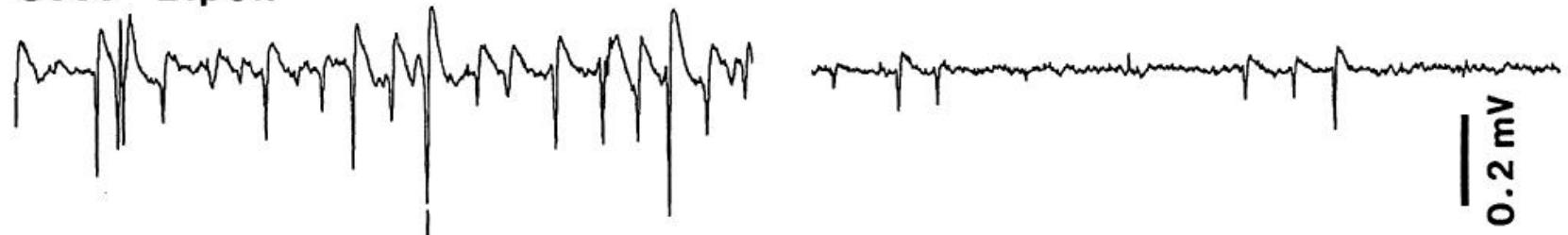

ENT.-Bipol.

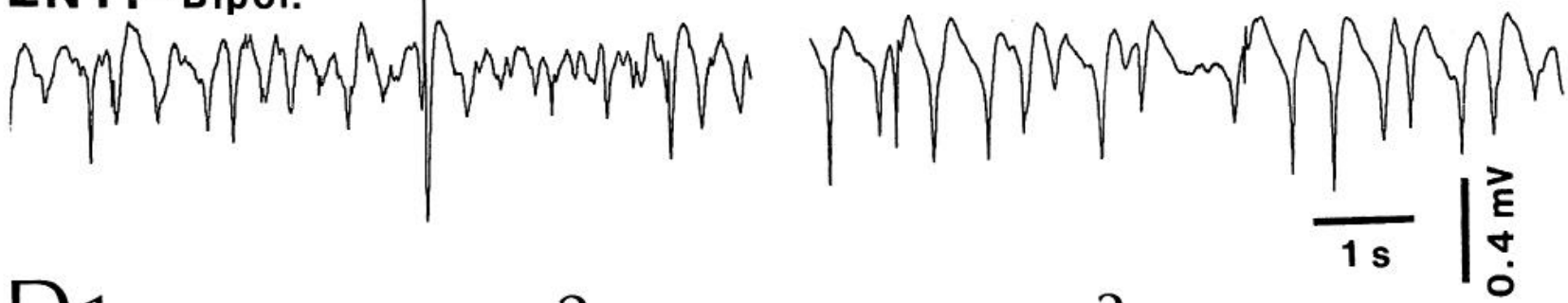

D1

CA1

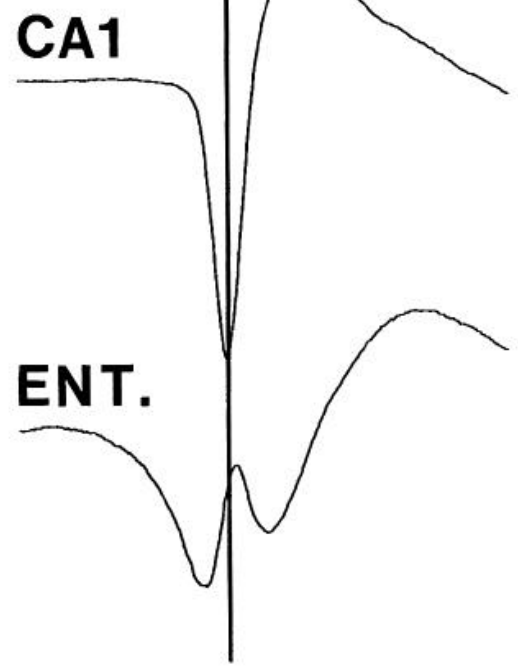

2

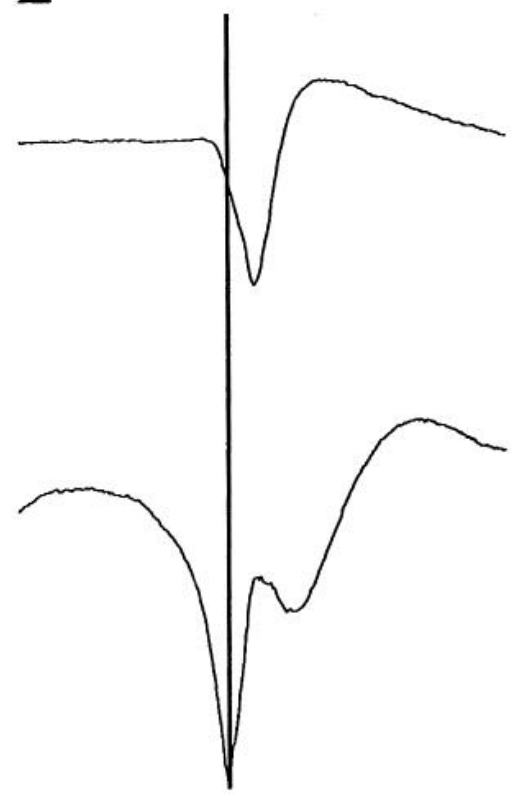

3

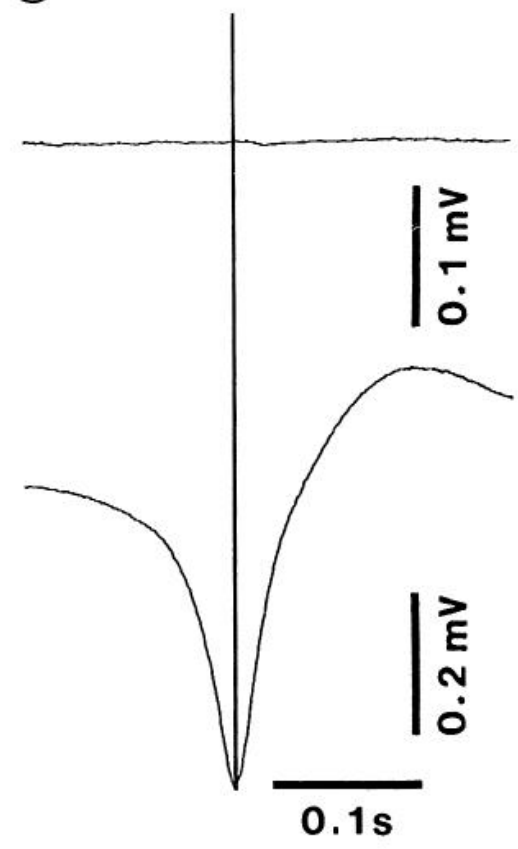




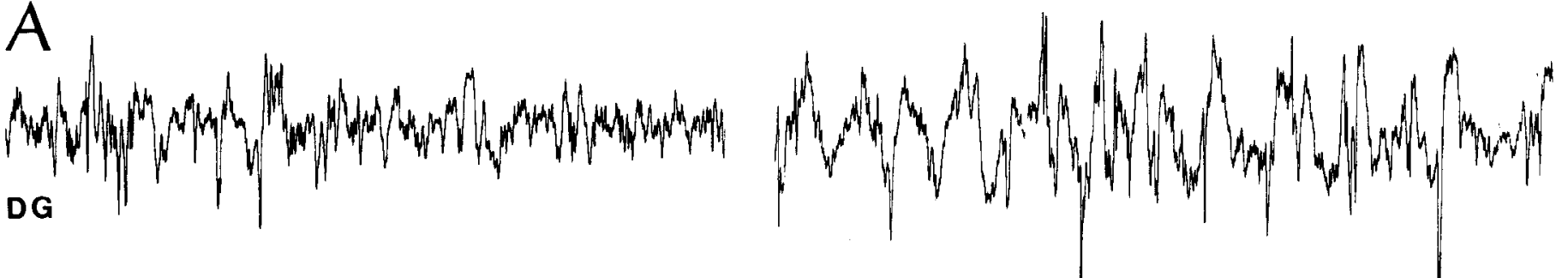

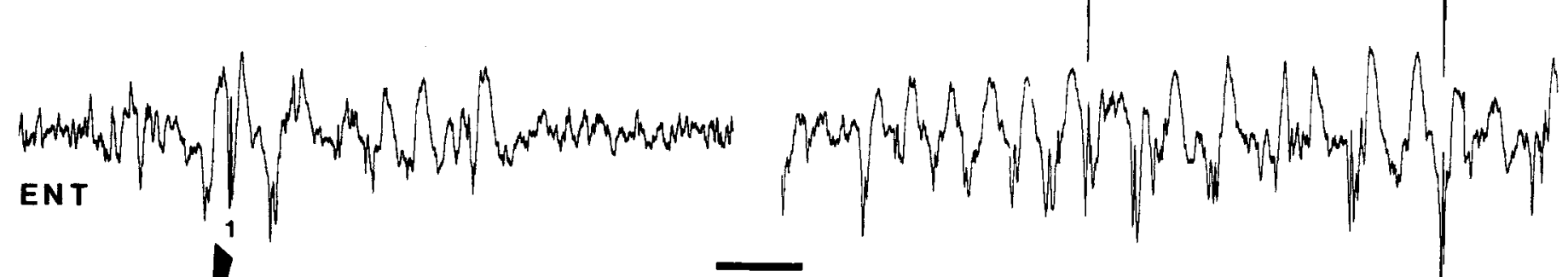
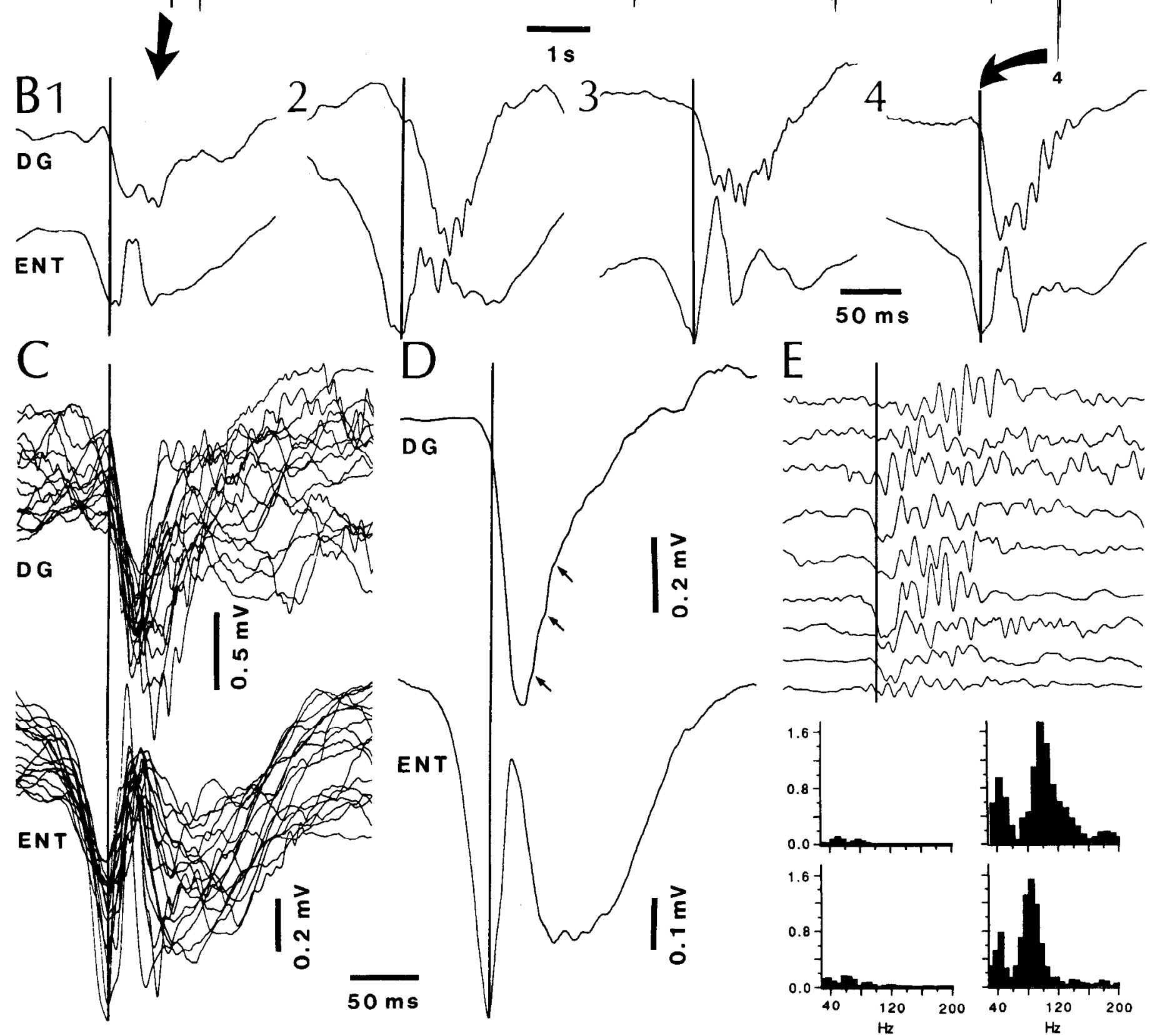

Figure 4. Simultaneous ENT and hippocampal recordings in naturally sleeping cats. $A$, Simultaneous recording of DG (molecular layer) and ENT cortex. On the left, spontaneous awakening from slow-wave sleep. On the right, period of deep slow-wave sleep. (BI-4), Simultaneously recorded DG and ENT SPs during slow-wave sleep with an expended time base. $C$, Superimposed DG (upper group of traces) and complex ENT SPs (lower group of traces) using the negative peak of ENT SPs as a temporal reference. $D$, Average of the traces shown in $C$. Arrowheads point to wavelets reflecting fast oscillations that are still evident in spite of averaging. $E$, High-frequency oscillation superimposed on DG SPs. Vertical line indicates 


\section{SIMPLE}
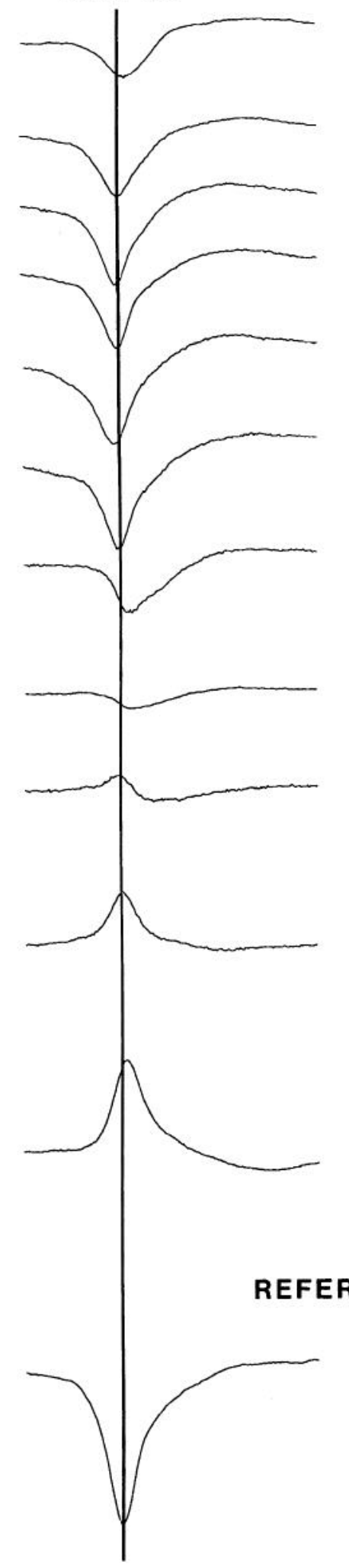

\section{COMPLEX}

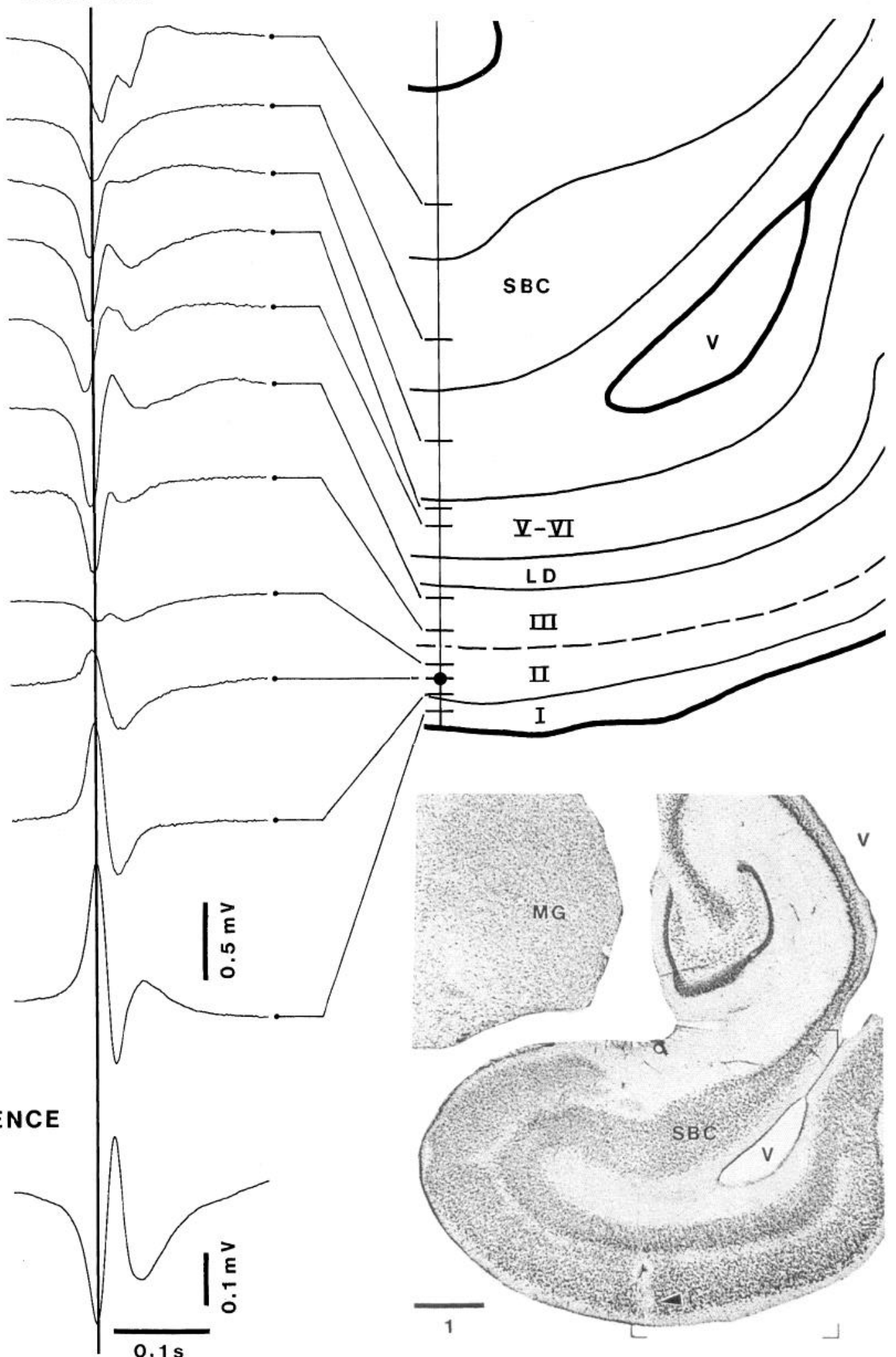

Figure 5.. Laminar analysis of simple and complex ENT SPs. A microelectrode was lowered in $100 \mu \mathrm{m}$ steps while a fixed bipolar electrode recorded ENT SPs $1.5 \mathrm{~mm}$ more caudally. The ENT SPs recorded with this fixed electrode were used as a temporal reference (bottom) to average potentials picked up by the moving electrode. In the lower right, the histological control of this electrode track is depicted. The arrowhead points to an electrolytic lesion that was made at the reversal of simple and complex SPs, in ENT layer II. The area enclosed in brackets is expanded in the scheme above. $M G$, medial geniculate thalamic nucleus; $S B C$, subiculum; $V$, ventricle. Scale bar, $1 \mathrm{~mm}$.

$\leftarrow$

the negative peak of complex ENT SPs. Traces were high-pass filtered at $30 \mathrm{~Hz}$. Time base in $C$ and $D$ is valid for $E$. Bottom, Power spectra in the $30-200 \mathrm{~Hz}$ range of DG activity before (left) and during (right) DG SPs. 


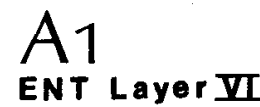

Figure 6. Activity of deep ENT neurons in relation to ENT SPs. $A$, Unit activity and simultaneously recorded focal waves. In $A l$, the ENT SPs that are marked by one and two asterisks are depicted with a faster time base in $A 2$ and $A 3$, respectively. Note that this neuron discharged single spikes in relation to simple ENT SPs but high-frequency spike bursts in relation to most complex SPs. $B$, Peri-SP histogram of neuronal discharges for complex (upper histogram) and simple (lower histogram) SPs. $C$ illustrates superimposed high-frequency bursts elicited by hippocampal stimuli.

ENT Layer VI
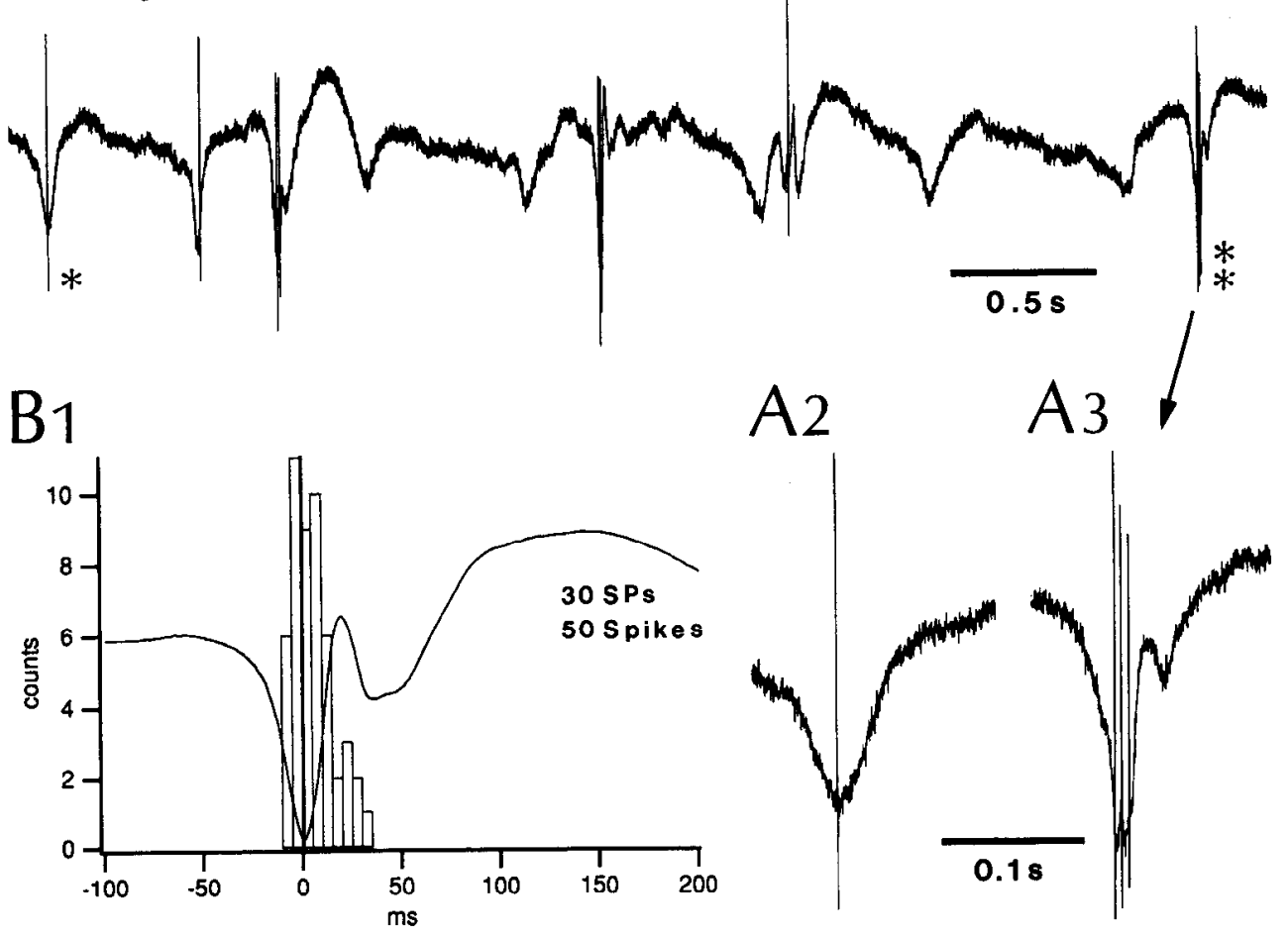

B2

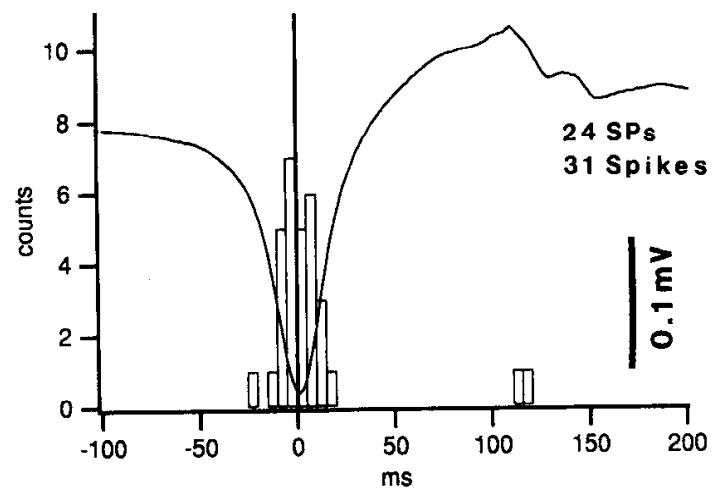

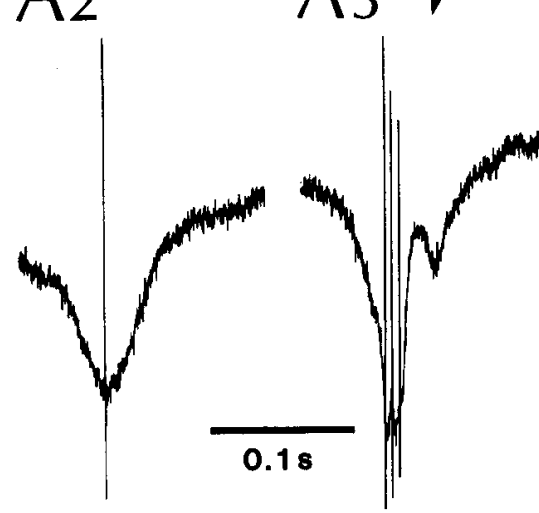

C

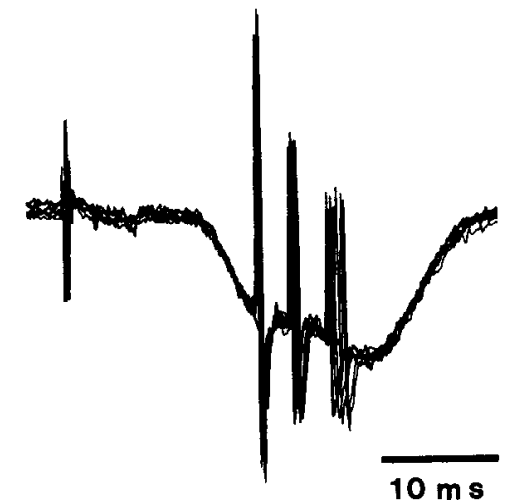

cellular unit recordings were performed in the ENT cortex, hippocampal formation, and amygdaloid complex of nine barbiturate-anesthetized cats. In the hippocampus, we restricted our analysis to the subiculum because it represents one of its main output station and receives convergent input from the amygdala (Krettek and" Price, 1977b; Room and Groenewegen, 1986b; Witter et al., 1989). To insure that differences in the timing of SP-related neuronal discharges recorded in these three structures could not be ascribed to variations in the placement of the ENT electrode used as a temporal reference across experiments, we recorded from two or three of these sites in most experiments (seven out of nine cats). This approach revealed that the differential temporal relations in neuronal firing described below were highly reproducible and independent of the placement of the ENT electrode used as a temporal reference.

Two types of analyses were performed to characterize SPrelated discharges. First, to investigate the timing of neuronal activities among these different types of neurons, peri-SP histograms of neuronal discharges were computed for simple and complex ENT SPs. Second, to characterize the implication of these different types of cells in the genesis of simple and complex SPs, a selectivity index describing the relative probability of neuronal discharge in relation to these two types of ENT SPS was computed according to the equation $P_{C} / P_{S}$, where $P_{C}$ and $P_{S}$ are the probability of neuronal discharge in relation to complex and simple SPs, respectively. In this analysis, spike bursts were considered as single events, like single spikes. Because this procedure was excessively time-consuming, it was only carried out for a restricted number of neurons having a signal to noise ratio greater than 10 .

ENT neurons. A total of 88 neurons were recorded in the ENT cortex, 28 in layers V-VI (dorsal to the lamina dessicans) and 60 in superficial layers. Based on histological reconstruction of microelectrode tracks and the polarity of simultaneously record- 


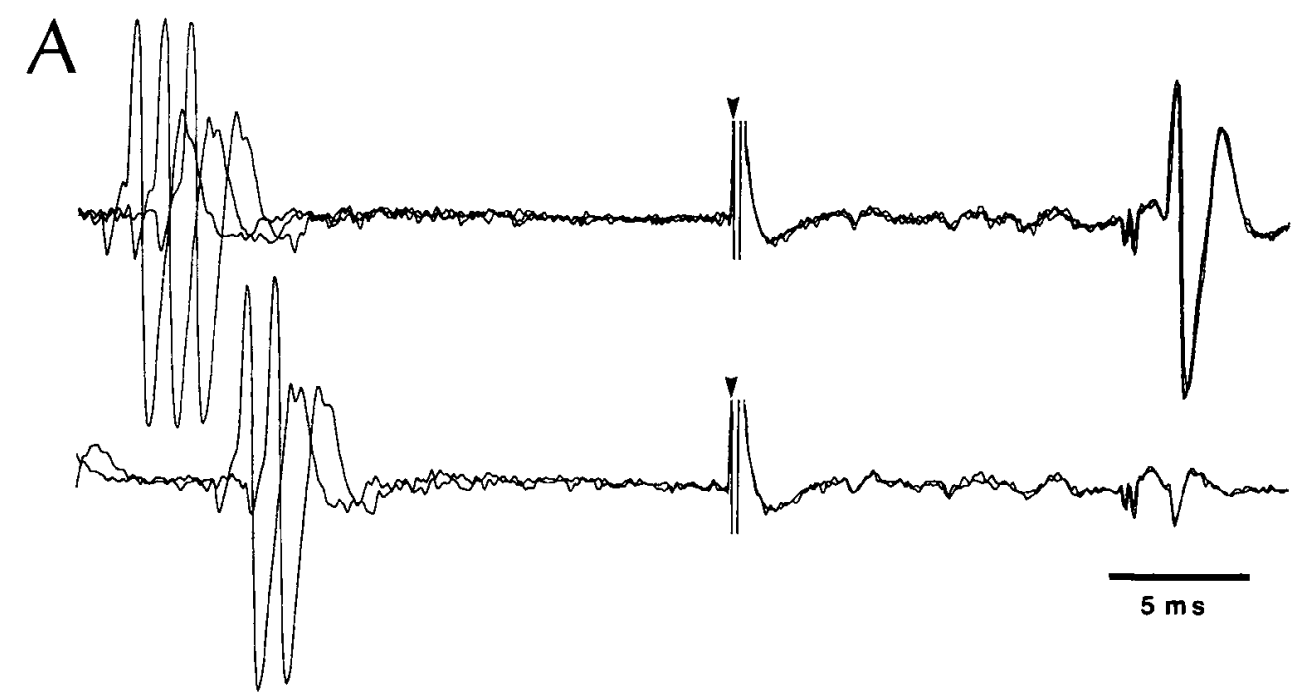

B

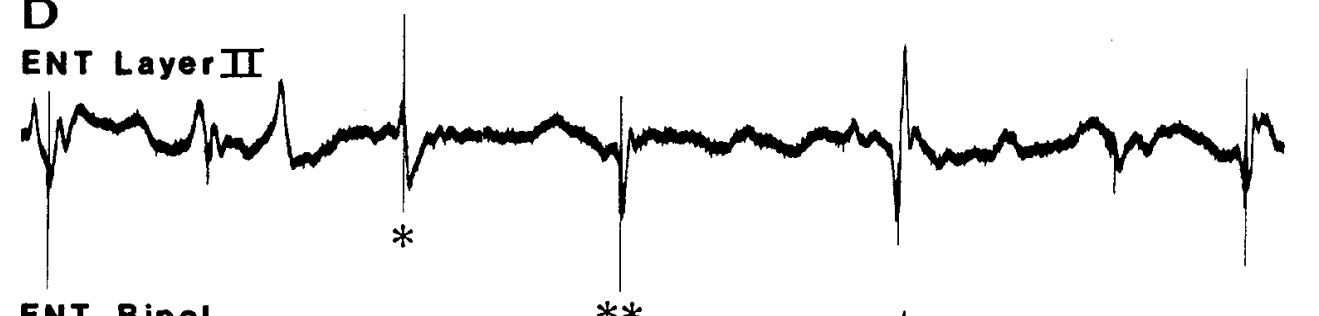

ENT Bipol.
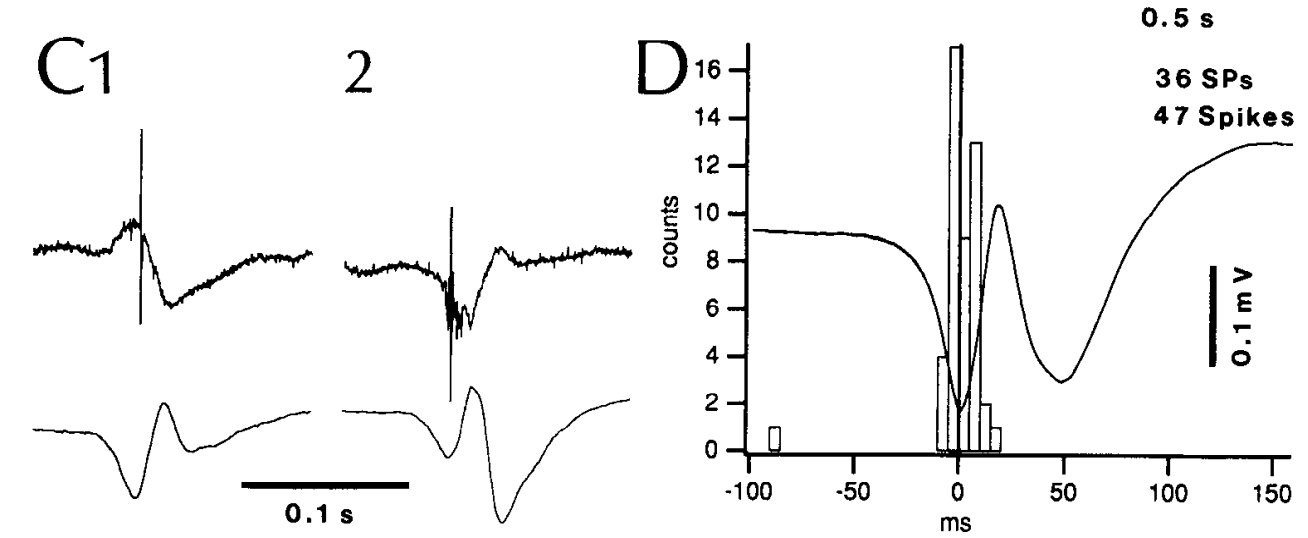

Figure 7. Presumed layer II ENT neurons discharge selectively in relation to complex SPs. A, Antidromic invasion from the hippocampal formation; collision test. Orthodromic spikes evoked by ENT stimuli. $B$, Unit activity (same cell as in $A$ ) and related focal waves (upper trace) are depicted with simultaneously recorded ENT SPs (reference) picked up by a bipolar electrode positioned $1.5 \mathrm{~mm}$ more caudal. The SPs marked by one and two asterisks are depicted with an expanded time base in $C 1$ and $C 2$, respectively. $D$, Peri-SP histograms of neuronal discharges for the same cell.

ed SPs (see below), superficial ENT neurons were tentatively subdivided in layer III neurons $(n=44)$ and layer II neurons $(n=16)$. In agreement with anatomical findings indicating that the majority of ENT neurons projecting to the hippocampus are located in layers II and III (Steward and Scoville, 1976; Ruth et al., 1982; Witter and Groenewegen, 1984), the probability of antidromic invasion in response to hippocampal stimuli was much higher for superficial than deep ENT neurons (18.3\% vs $5.6 \%$ ). The latency of antidromic responses varied considerably from 3 to $16 \mathrm{msec}(7.52 \pm 3.2 \mathrm{msec})$. A few superficial ENT cells could be ortho or antidromically activated from a neighboring site in the ENT cortex. The latency of these responses ranged from 3 to $7.5 \mathrm{msec}$.

Computation of peri-SP histograms of neuronal discharges re- vealed a clear relation between the laminar location of ENT neurons and their SP-related activities. Deep EN'I neurons fired in relation to both simple and complex SPs but tended to discharge more vigorously in relation to complex SPs. In particular, $12 \%$ of the cells discharged single spikes in relation to simple SPs but fired stereotyped spike bursts $(250-350 \mathrm{~Hz})$ in relation to complex SPs (Fig. 6). These cells responded with similar high-frequency bursts in response to orthodromic stimuli (Fig. $6 C)$. The timing of SP-related discharges varied slightly from cell to cell but, in most cells, the peak of the peri-SP histogram was located between -10 and $0 \mathrm{~ms}$ with respect to the peak of the reference SPs. This was true for both simple and complex SPs (see Fig. 12B).

In contrast, layer II neurons, some of them antidromically 
A

ENT Layer III

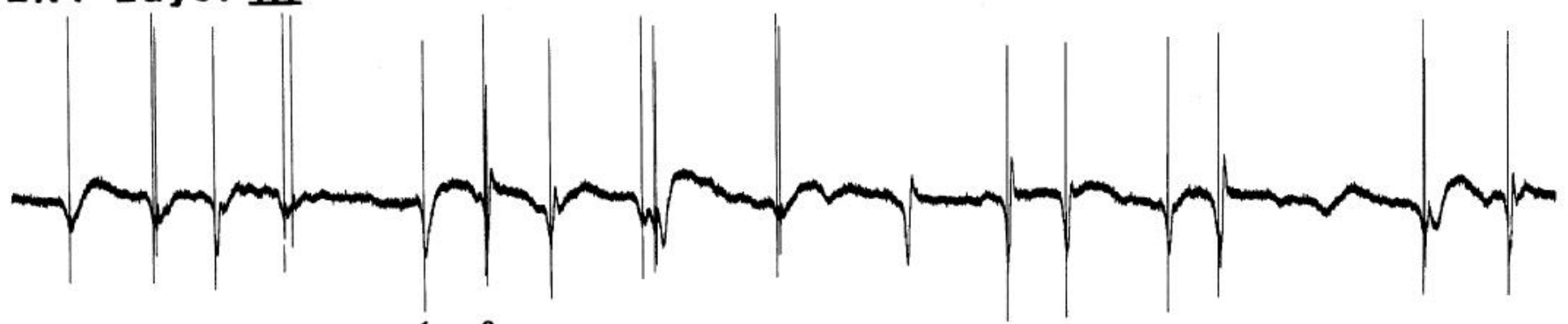

ENT Bipol.

B1

2

3

4

C
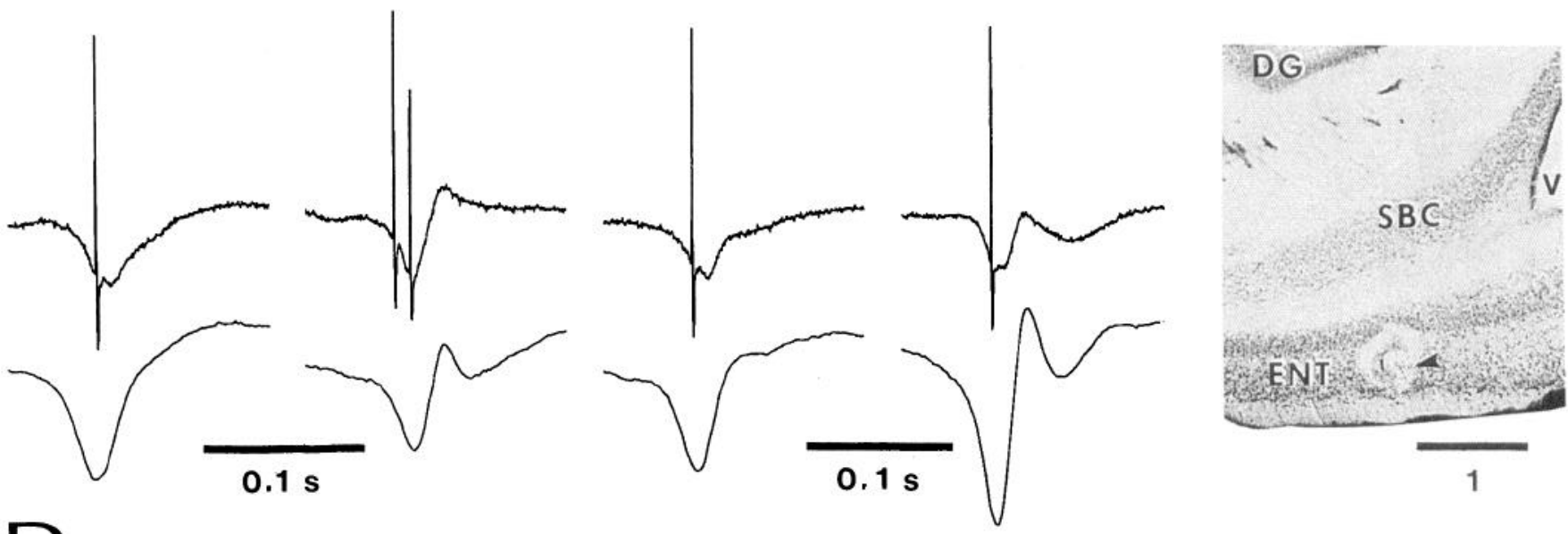

D
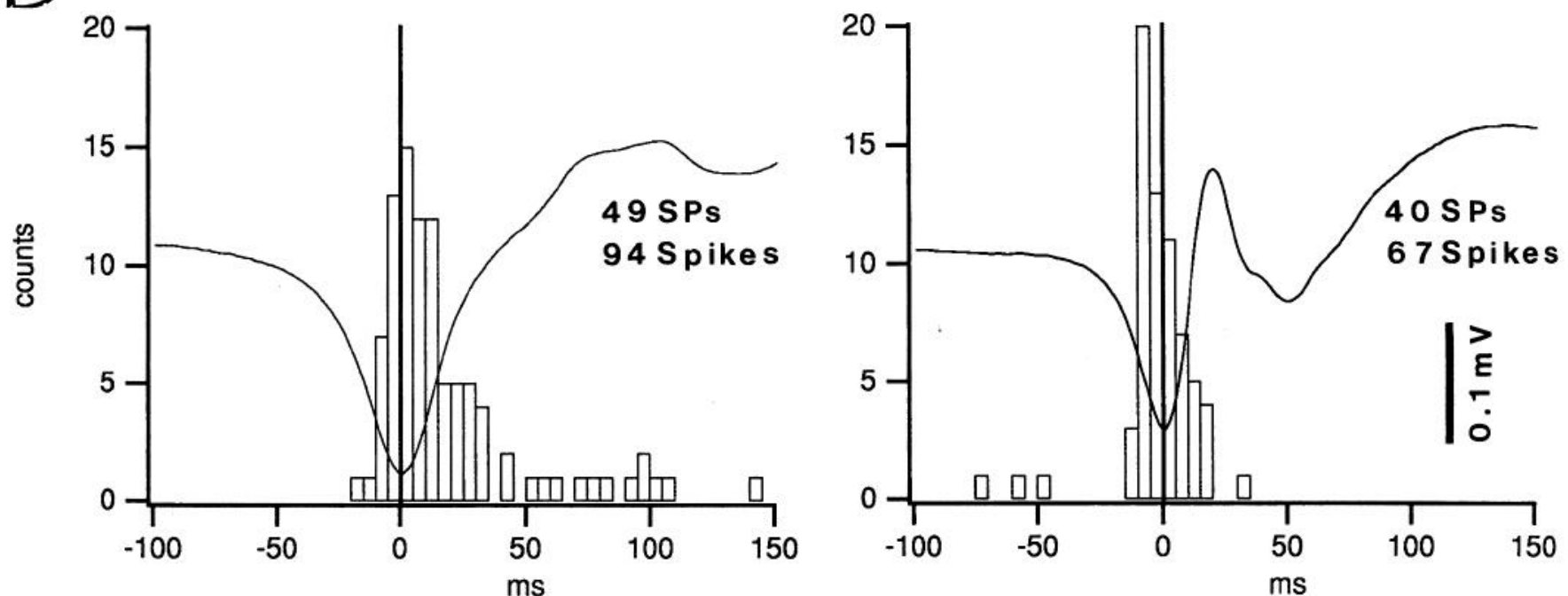

Figure 8. SP-related activity of layer III ENT neurons. A, Unit activity and related focal waves (upper trace) are depicted with simultaneously recorded ENT SPs (reference) picked up by a bipolar electrode positioned $1.5 \mathrm{~mm}$ more caudal than the microelectrode used for unit recordings. $B$, Four examples of SP-related unit activity illustrated with a faster time base. The SPs shown in $B 1-2$ correspond to the SPs marked by 1 and 2 
invaded from the hippocampal formation, discharged almost exclusively in relation to complex SPs. An example of this is shown in Figure 7. This neuron was antidromically invaded from the hippocampal formation with a latency of $15 \mathrm{msec}$ (collision test in Fig. 7A) and fired exclusively in relation to complex SPs (Fig. 7B,C). Like most layer II neurons (see Fig. 12D), the majority of SP-related spikes fired by this cell occurred between -5 and $10 \mathrm{msec}$ of the peak of reference SP. Note that the focal activity that was simultaneously recorded with the same microelectrode indicates that this cell was located at the site of reversal of SPs as evidenced by the variable polarity of locally recorded complex SPs (Fig. 7C1,C2). This phenomenon explains the low amplitude of averaged SPs observed in layer II during laminar analyses of SPs (see Fig. 5). We used this criteria in conjunction with histological controls to distinguish layer II from layer III neurons.

The selectivity indexes of layer II ENT neurons varied between 25.3 and 138 (average of $81.6 ; n=5$ ) compared to a range of 1.6 to 3.18 for deep ENT neurons (average of $2.1 ; n$ $=6$ ). In other words, layer II neurons were 25 to 138 times more likely to fire in relation to complex than simple SPs. In spite of the small number of neurons tested, the difference in selectivity between layer II and deep ENT neurons was found to be statistically significant with a $t$ test $(p<0.05)$.

Finally, layer III ENT neurons, discharged single spikes or spike doublets in relation to both simple and complex SPs. The selectivity indexes of layer III neurons varied from 1.2 to 28 but averaged $15.89(n=7)$. A $t$ test indicated that the selectivity of layer III neurons was significantly higher that of deep ENT neurons $(p<0.05)$. Figure 8 illustrates the SP-related activity of a layer III ENT neuron that was active in relation to simple and complex SPs. Note that in contrast with layer II ENT cells, the polarity of locally recorded SPs does not change from one complex SP to the next. In most layer III ENT cells, the peak of peri-SP histograms was located between -10 and $15 \mathrm{msec}$ of the peak of the reference simple and complex SPs (see Fig. $12 C$ ).

Subicular neurons. A total of 67 subicular neurons were recorded. As many as $60 \%$ of them were orthodromically activated by hippocampal stimulation with a mean latency of $13.9 \pm 7.3$ msec at threshold stimulation intensities. Most of these orthodromic responses were clearly plurisynaptic in view of the fact that increasing the intensity of stimulation gradually reduced re sponse latencies by as much as $8 \mathrm{msec}$. At high stimulation intensities, the shortest orthodromic latencies observed in response to hippocampal stimulation was $3 \mathrm{msec}$. No antidromic responses to hippocampal stimuli were observed.

Two types of subicular neurons could be distinguished on the basis of their SP-related discharges. A minority of the cells (36\%) discharged single spikes or low-frequency spike doublets in relation to simple and complex SPs usually within -10 to 15 $\mathrm{ms}$ of the reference SPs peak (Fig. 9). Two-thirds of these cells consistently discharged more than $15 \mathrm{msec}$ later in relation to complex than simple SPs (not illustrated). The selectivity index of this group of neurons ranged between 1.3 and $5(n=7)$.

The majority (64\%) of subicular neurons fired almost exclu- sively in relation to complex SPs, most SP-related spikes occurring 15-40 msec following the peak of the reference SPs (see Fig. 12E). In these cells, SP-related discharges usually consisted of single spikes or, less frequently, of spike doublets with interspike intervals between 5 and $15 \mathrm{msec}$. Two examples of this are shown in Figure 10, where the activity of several subicular neurons along with simultaneously recorded focal waves is depicted (see caption for details). Note that these cells never discharged in relation to simple SPs during the illustrated period in spite of the fact that simple SPs were as frequent as complex SPs at the prevailing level of anesthesia. Accordingly, the selectivity index of these cells ranged between 18 and $141(n=7)$.

Neurons of the basolateral amygdaloid complex. The fact that no subicular neurons discharged before ENT SPs implied that these potentials do not represent a synaptic response to a synchronous population discharge of hippocampal neurons. In search of another possible source for ENT SPs, unit recordings were performed in the basolateral amygdaloid complex that projects to both the subiculum and ENT cortex in cats (layers IIVI in cats; Krettek and Price, 1977b; Room and Groenewegen, 1986b). A total of 72 neurons were recorded in this nuclear complex: 23 in the lateral nucleus, 42 in the BL nucleus, and 7 in the basomedial nucleus. Because neurons of the lateral and basomedial nuclei discharged in phase or after the peak of reference SPs, they will not be discussed further in this context.

In the BL nucleus, orthodromic responses to ENT stimulation could be elicited in the majority of tested neurons $(64 \%, n=$ 25 ). In most cases, the latency of orthodromic responses ranged between 5 and 9 msec but a few were activated at longer latencies $(>14 \mathrm{msec})$, thus resulting in an average latency of $9.8 \pm$ 4.1 msec. Only $12 \%$ of tested neurons $(n=25)$ could be antidromically invaded from the ENT cortex and responses latencies ranged between 7 and $10 \mathrm{msec}$.

BL neurons discharged in relation to simple and complex SPs with selectivity indexes ranging between 1 and $3.27(n=7)$, the lowest selectivity found in the amygdalo-hippocampal circuit. In contrast with other neuronal types recorded in this study, most neurons of the BL nucleus discharged well before the peak of simple SPs. Examples of such neurons are provided in Figure 11 along with the histological control showing where the depicted neurons were recorded (see caption). The proportion of BL neurons that had the mode of their peri-SP histograms preceding ENT SPs by more than $5,10,15$, and $20 \mathrm{msec}$ was $85 \%$, $60 \%, 48 \%$, and $34 \%$ of the cells, respectively (see Fig. 12A1).

The temporal relation between the discharges of $\mathrm{BL}$ neurons and complex SPs was different. Computation of peri-SP histograms of neuronal discharges revealed that the majority of BL neurons discharged in phase with the negative peak (within \pm 10 msec) of complex SPs (see Fig. 12A2). Only $11 \%$ of the cells had the mode of their peri-SP histogram preceding the peak of complex ENT SPs by more than $10 \mathrm{msec}$ (compared to 60\% for simple ENT SPs). Nevertheless, as much as $29.6 \%$ of the cells displayed significant increased in firing probability, here defined as twice the average firing rate, more than $20 \mathrm{msec}$ before the peak of reference complex ENT SPs.

Figure 12 depicts grouped peri-SP histograms for neuronal

$\leftarrow$

in $A . C$, Histological control showing where this neuron was recorded. Arrowhead points to electrolytic lesion that marks the recording site. Calibration bar in millimeters. $D$, Peri-SP histograms of neuronal discharges for simple (left) and complex (right) ENT SPs. DG, dentate gyrus; $S B C$, subiculum; $V$, ventricle. 

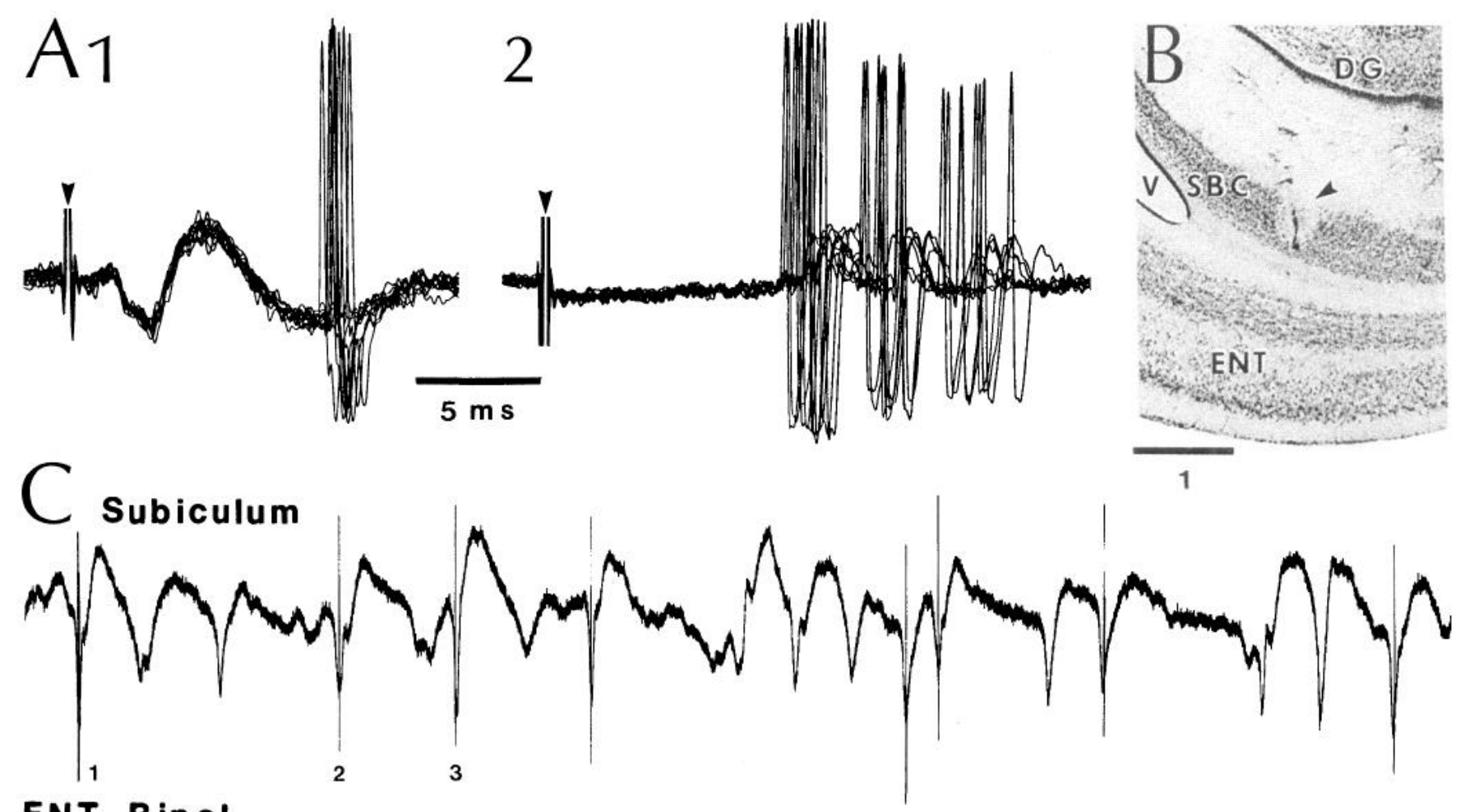

ENT Bipol.

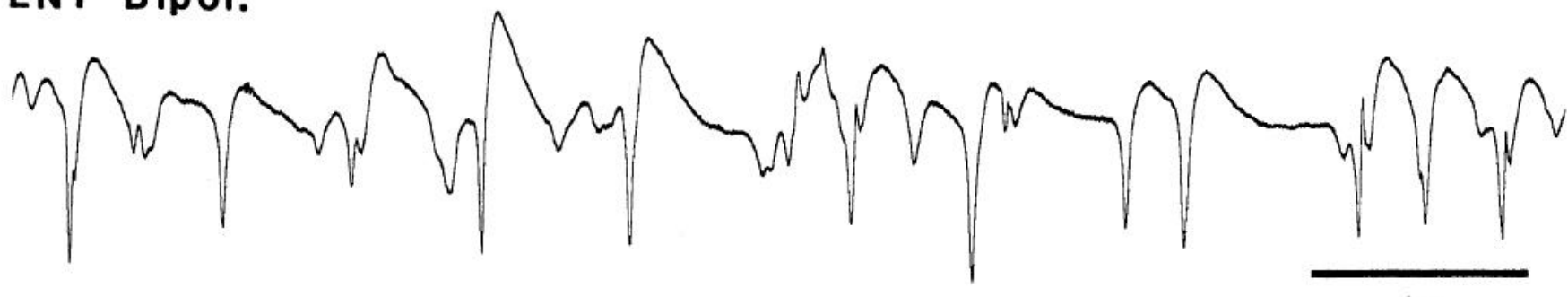

D1

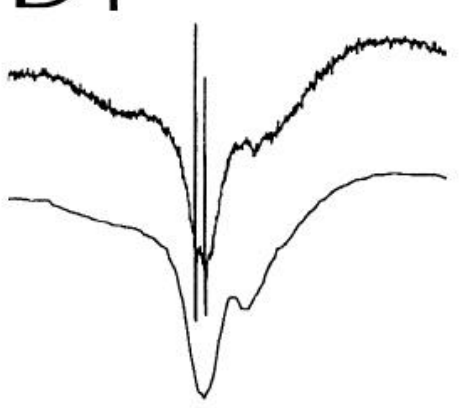

2
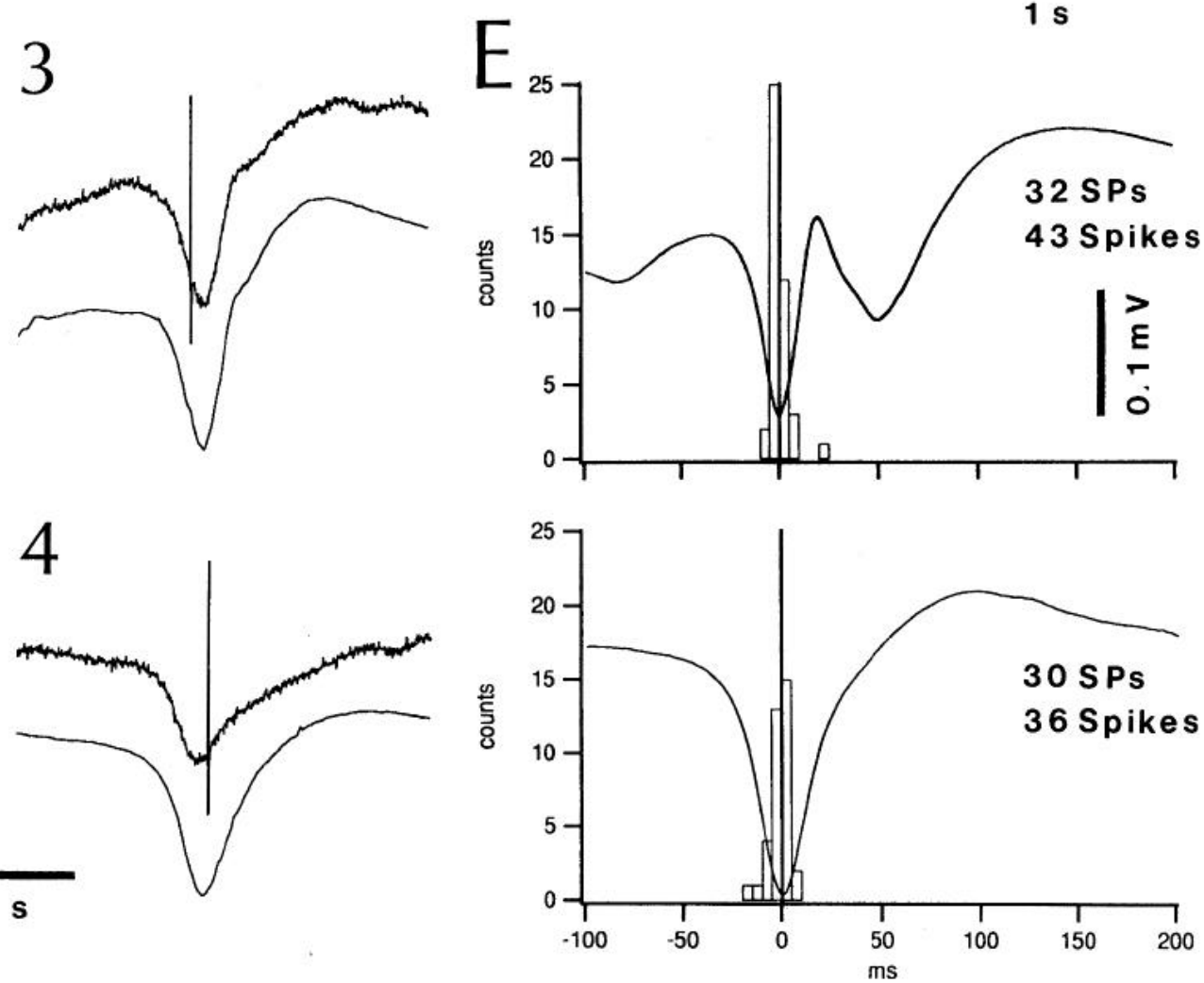
samples recorded in the BL nucleus (Fig. 12A), layers IV-VI (Fig. 12B), III (Fig. 12C), and II (Fig. 12D) of the EN'T cortex as well as in the subiculum (Fig. 12E). In Figure 12E, only subicular neurons discharging sclcctivcly in relation to complex SPs were included. The relation between neuronal discharges and SPs is illustrated for both simple (left) and complex (right) ENT SPs with the exception of layer II and subicular neurons. In relation to simple SPs (Fig. 12AI-CI), note that the mode of peri-SP histograms gradually shifts to the right from the BL nucleus to layer III ENT neurons. However, although the peak of population histograms occur earlier in BL neurons than in deep ENT cells, their probability of discharge initially appears to rise at the same time. In relation to complex SPs (Fig. 12A2$C 2, D, E$ ), the firing probability of deep ENT neurons and $\mathrm{BL}$ cells increases in parallel. Firing in these two population of cells is then followed by that of superficial ENT neurons and, 15-35 msec later, by that of subicular cells.

\section{Excitotoxic and electrolytic lesions of ENT inputs}

The differential temporal relations in neuronal discharges described above suggest that the BL nucleus generates a synchronized population event that is critical to the genesis of simple ENT SPs. To test this possibility, unilateral kainic acid lesions of the amygdaloid complex were performed in three cats. Figure 13 illustrates the most extensive lesion obtained with this method. This lesion encompassed the rostral two-thirds of the amygdala but spared its caudal part, the ENT cortex (Fig. 13B) and the temporal pole of the hippocampus (Fig. 13C). As shown in Figure 14, this lesion abolished ENT SPs but had no effect on the activity of the contralateral ENT cortex. Smaller excitotoxic lesions encompassing part of the $\mathrm{BL}$ and lateral nucleus with no involvement of neighboring cortices $(n=2)$ had identical effects. Control lesions that were placed more rostrally, in the anterior amygdaloid area $(n=1)$, or more dorsally, in the pallidum and putamen $(n=1)$, did not aholish ENT SPs.

In two experiments, electrolytic lesions that were placed in the BL nucleus to mark an electrode track, markedly decreased the frequency but not the amplitude of ENT SPs. Histological examination revealed that these lesions destroyed the ventral tip of the BL nucleus. Other electrolytic lesions placed in the subiculum, central or lateral amygdaloid nuclei had no effect on ENT SPs.

To test the possibility that ENT SPs represent a synaptic response to cortical or thalamic inputs reaching both the ENT cortex and amygdala, an extensive kainic acid lesion was placed in the thalamus of one cat. In another animal, most of the neocortex was destroyed by applying silver nitrate crystals to the cortical surface. In both cats, the amplitude and frequency of SPs appeared normal. Finally, an extensive but admittedly incomplete hippocampal lesion (40 electrolytic lesions distributed along the septotemporal axis of the hippocampal formation) had no obvious effects on ENT SPs $(n=1)$.

\section{Discussion}

By contrast with thalamocortical circuits where neuronal events often have clear functional correlates, the meaning of amygdalocortical activities is difficult to conceive and to define operationally. As a result, amygdalocortical circuits have received comparatively less attention. In this study, we used an approach that yields insights in the processes governing neuronal interactions within large-scale networks, independently of their informational content. This approach consists in studying neuronal events related to spontaneous synchronized activities (such as spindling in thalamocortical circuits) and to infer the cellular relations underlying them. More precisely, we have tracked the sequence of neuronal events contributing to the generation and propagation of previously unknown population phenomena, termed sharp potentials (SPs), that occur in the ENT cortex during EEG-synchronized states.

Unit recordings and lesioning techniques revealed that the BL nucleus plays an essential role in the generation of SPs and that the ENT cortex is not a passive receiver of BL inputs but is endowed with an inhibitory mechanism allowing layer II ENT neurons to gate the transfer of incoming inputs to the hippocampal formation. In the following discussion, we will examine the evidence supporting these conclusions and consider their implications for the elaboration of normal and pathological activities in the amygdalo-hippocampal network.

\section{Role of the BL nucleus in the genesis of ENT SPS}

Two lines of evidence suggest that the BL nucleus plays an essential role in the gencsis of ENT SPs. First, within the amygdalo-hippocampal circuit, BL neurons displayed the earliest signs of increased discharge probability in relation to simple ENT SPs, as much as $40 \mathrm{msec}$ before their peak. Second, amygdala lesions abolished ENT SPs whereas lesions of the neocortex, thalamus, parts of the putamen and globus pallidus or anterior amygdaloid area did not. Moreover, previous findings indicate that the BL nucleus contributes an excitatory glutamatergic projection to the ENT cortex. Indeed, it was reported that the BL nucleus projects to layer II-VI of the ENT cortex (Krettek and Price, 1977b; Room and Groenewegen, 1986b) and that cortical projections of the BL nucleus arise from non-GABAergic, pyramidal-shaped neurons (Paré et al., 1994) believed to use glutamate as a transmitter (Nitecka and Ben-Ari, 1987; McDonald and Augustine, 1993; Paré and Smith, 1993). Moreover, Colino and Fernández de Molina (1986) reported that BL stimulation evokes depth negative-surface positive waves followed by a slower potential of opposite polarity in the ENT cortex. As is the case for ENT SPs, the depth negative component of this field potential reversed polarity around layer II and was associated with an increased probability of neuronal discharges. Similarly, Finch et al. (1986) found that amygdala stimulation evokes short-latency EPSP-IPSP sequences in most classes of ENT ncurons including physiologically identified layer II ENT cells.

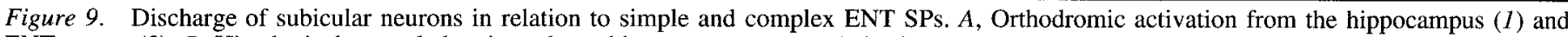

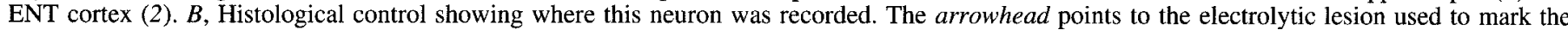

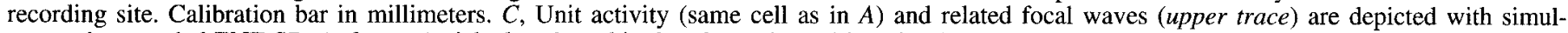

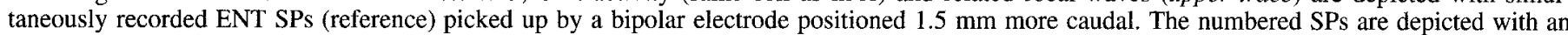

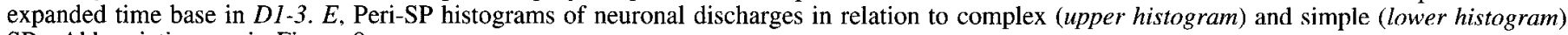
SPs. Abbreviations as in Figure 8. 

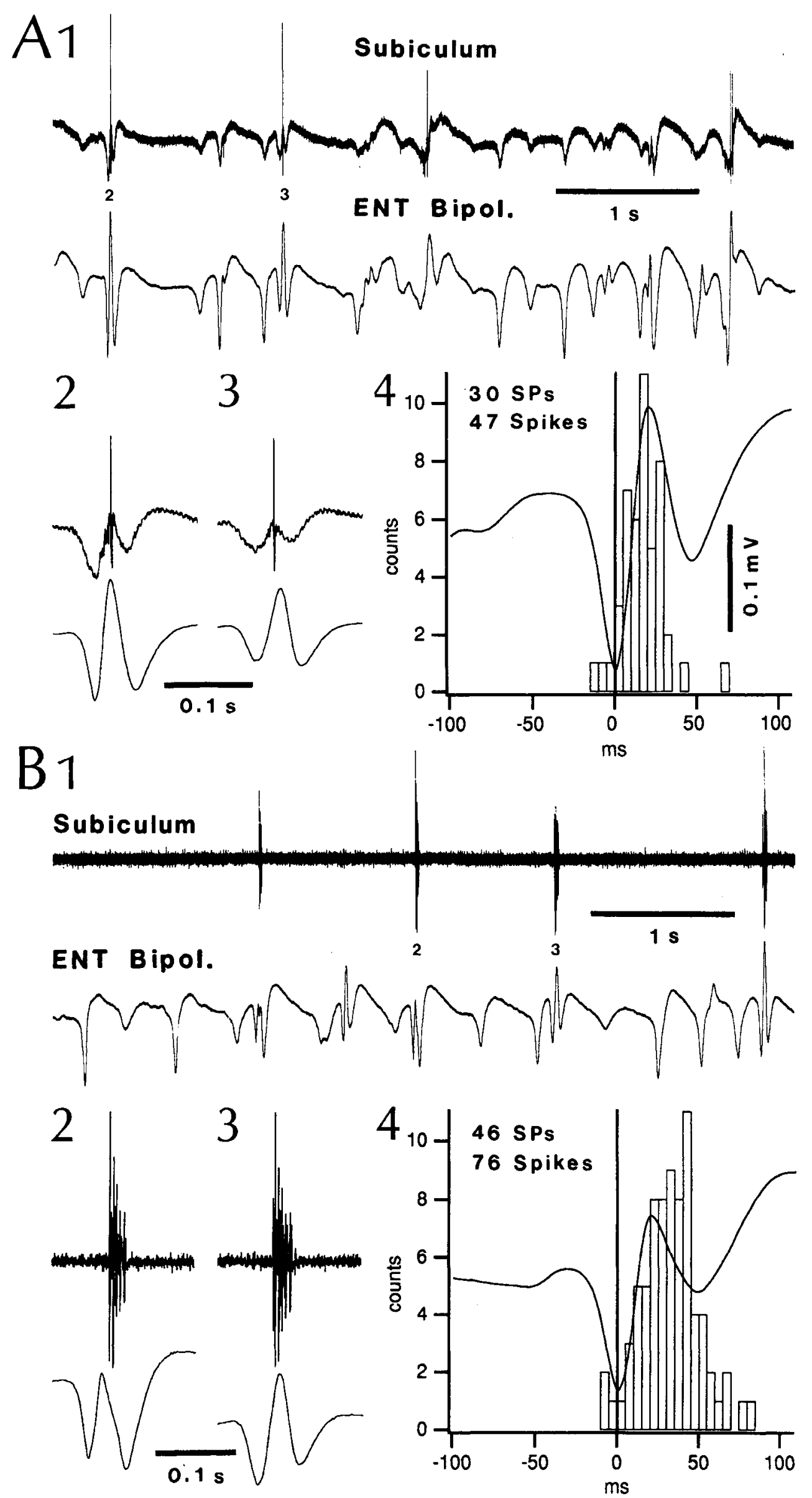

Figure 10. Selective discharge of subicular neurons in relation to complex ENT SPs. $A$ and $B$, Two subicular recording sites. 1 , Unit activity and related focal waves (upper trace) are depicted with simultaneously recorded ENT SPs (reference) picked up by a bipolar electrode positioned $1.5 \mathrm{~mm}$ more caudal. 2-3, SP-related activity depicted with an expanded time base. 4 , Peri-SP histogram of neuronal discharge. Unit activity in $B$ was highpass filtered at $300 \mathrm{~Hz}$. 
The mechanisms allowing the BL nucleus to generate SPrelated population bursts are unclear. In light of the rhythmic nature of SPs, it could be hypothesized that BL neurons are endowed with intrinsic membrane properties allowing them to generate slow oscillations that periodically give rise to spike discharges. In this hypothetical scheme, the oscillatory behavior of BL neurons would be synchronized by intranuclear axon collaterals (McDonald, 1992) and be relayed to the ENT cortex by amygdalofugal axons. However, intracellular studies of BL neurons in vitro (Washburn and Moises, 1992; Rainnie et al., 1993) suggest that their intrinsic membrane properties could not sustain such oscillatory behavior. Moreover, intracellular recordings of BL neurons obtained in vivo (Dong and Paré, 1994) revealed that SP-related BL discharges arise from EPSPs that often give rise to spike doublets but were not preceded by hyperpolarizing potentials. However, a proportion of these cells generated similar spike doublets in response to depolarizing current pulses thus indicating that their ability to generate high threshold bursts may be involved in the amplification of SP-related synaptic events. These findings lead us to favor the view that the BL nucleus plays an essential role in SP genesis by transforming and amplifying weak extra-amygdaloid synaptic inputs into synchronized neuronal events through its extensive system of intranuclear connections and the intrinsic properties of its constitutive elements. Because the ENT cortex has reciprocal connections with the BL nucleus, it is a good candidate for initiating and reinforcing the cxplosive SP-related discharge of BL ncurons. However, the abolition of SPs by amygdala lesions indicates that the BL complex plays an essential role in the genesis of SPs. The generation of complex ENT SPs will be considered below.

\section{Cellular correlates of SPS in the ENT cortex}

The laminar profile and unit activities observed in relation to simple SPs suggest that BL inputs generate excitatory post-synaptic potentials in a large number of layer III-VI ENT neurons with dendrites perpendicular to the cortical surface. Stellate neurons and other cells with radially oriented dendrites probably have a negligible contribution to SP-related field potentials as they generate closed fields. Since the ENT cortex is characterized by intracortical connections that predominantly run from deep to superficial ENT layers (Köhler, 1986, 1988; Witter et al., 1989), it is likely that superimposed on the active sink generated by amygdaloid inputs are locally generated synaptic events. These local interactions may account for the subtle but reproducible shift to the right of the SP's peak as the recording electrode was displaced from deep to superficial ENT layers. Furthermore, this factor could explain the delayed discharge of layer III neurons with respect to that of deep neurons in relation to SPs. As to the silence of layer II neurons during simple SPs, it is consistent with previous findings suggesting that the behavior of stellate cells, which constitute the majority of neurons in layer II (Ramón y Cajal, 1911; Lorente de Nó, 1933), is dominated by inhibition (reviewed in Jones, 1993). Indeed, in vivo and in vitro studies have shown that synaptic stimuli evoke GA$\mathrm{BA}_{\mathrm{A}}$ and $\mathrm{GABA}_{\mathrm{B}}$ IPSPs that are powerful enough to prevent EPSPs from eliciting action potentials in stellate cells at low stimulating rates (Finch et al., 1986, 1988; Jones, 1990a,b). These IPSPs are believed to be mediated by local ENT interneurons (Finch et al., 1988; Jones and Buhl, 1992). In addition, Chrobak and Buzsáki (1994) have observed that deep ENT layers are selectively activated in relation to hippocampal sharp waves. Consistent with these observations is the presence of perisomatic arrays of GABA-immunoreactive punctate structures that probably represent inhibitory synaptic terminals around layer II cells (Köhler et al., 1985).

From the standpoint of the ENT cortex, the main difference between simple and complex SPs was the activation of layer II neurons and the subsequent occurrence of a short-lasting surface negative-depth positive spiky potential. This potential probably reffects the occurrence of an active sink mediated by the longitudinal connections of layer II neurons that predominantly end in layer Ib (Witter et al., 1986). This sharp potential was then followed by a depth negative-surface positive wave that may represent reentrant hippocampal inputs since they mostly end in deep ENT layers (Room and Groenewegen, 1986a; Witter et al., 1989).

What factors account for the selective activation of layer II neurons in relation to complex ENT SPs? Since complex SPs usually are of larger amplitude than simple SPs, one possibility is that the discharge of layer II ENT neurons only occurs when a critical number of BL neurons and deep ENT cells fire in a sufficiently narrow time window to overcome the IPSPs that normally prevent the activation of layer II cells (Finch et al., 1986, 1988; Jones, 1990a,b). Although this explanation may account for some complex SPs, the fact that BL neurons generally discharged in phase with the negative peak of complex SPs indicates that another mechanism is involved. In agreement with this, we observed that most complex SPs were preceded, with an abnormally short interval, by simple SPs of low amplitude thus suggesting that the following complex SPs constituted a rebound phenomenon (see Figs. 10, 11, 12A2). It is known that layer II stellate cells can generate rebound discharges at the end of hyperpolarizing pulses, an electroresponsive behavior that is believed to be mediated by the activation of a $\mathrm{Q}$-like potassium current and by that of low-threshold sodium and calcium conductances (Jones, 1990a; Alonso and Klink, 1993; Klink and Alonso, 1993). Thus, it is possible that the activation of layer II stellate cells in relation to these complex SPs represents a rebound response mediated by these active conductances but triggered by EPSPs occurring during the shallow IPSPs related to the preceding simple SPs.

So far, we have been unable to identify a neuronal population that reliably fires before complex ENT SPs. However, both BL and deep ENT neurons occasionally fired well before complex SPs. Thus, the possibility must be considered that rebound complex SPs may be triggered by one of several structures. On the other hand, it is possible that the timing of $\mathrm{BL}$ discharges in relation to complex SPs appears delayed in peri-SP histograms because of a feedback from the ENT cortex that would prolong their activity. In support of this view is the fact that amygdala lesions also abolished complex ENT SPs. More experiments will be required to settle this issuc.

\section{Propagation of ENT SPs to the hippocampal formation}

Since the bulk of ENT-hippocampal projections arise in layer II stellate neurons (Ruth et al., 1982; Witter and Groenewegen, 1984), their selective activation in relation to complex SPs probably accounts for the observation that simple ENT SPs have no hippocampal correlate. Under light barbiturate anesthesia, the hippocampal correlates of complex ENT SPs were observed at several levels of the trisynaptic hippocampal loop (Deadwyler et al., 1975) including CA1 and the subiculum. On average, the negative peak of complex ENT SPs occurred 20-30 msec before that of CA1 SPs. This delay and the laminar profile of CA1 SPs 

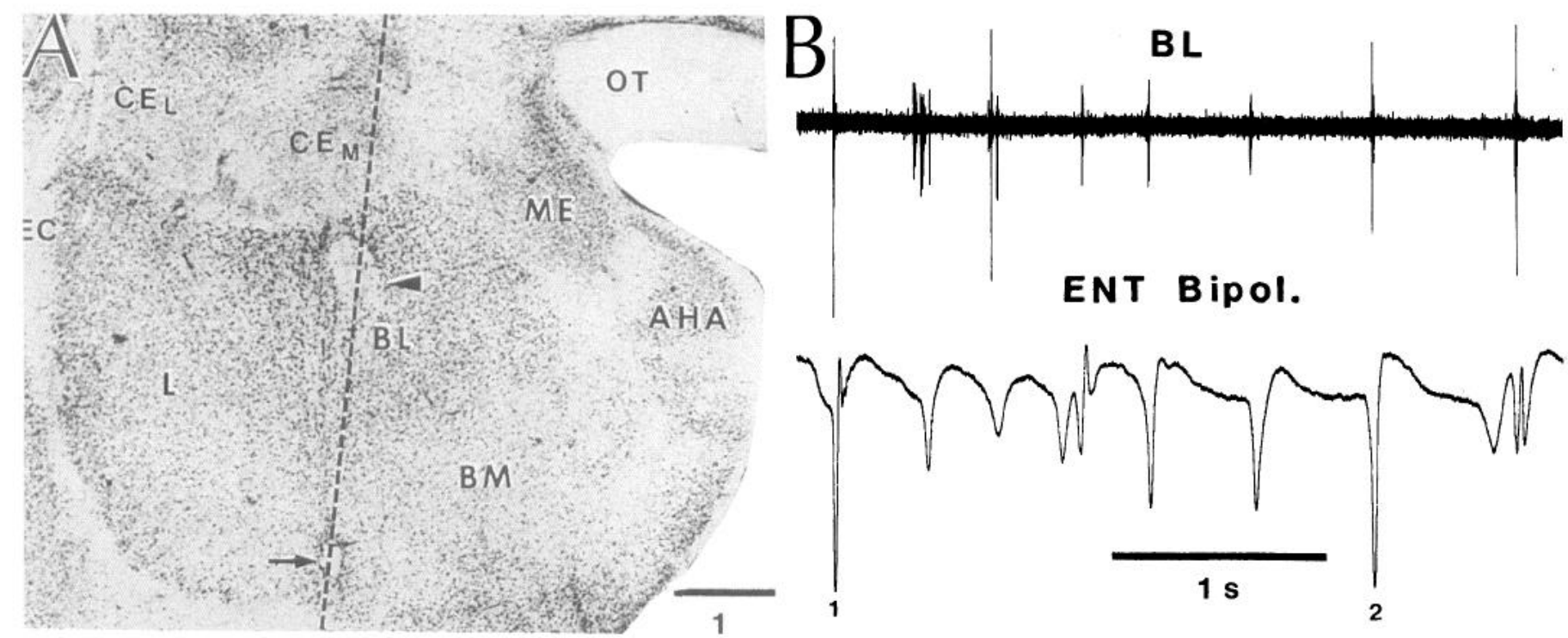

ENT Bipol.
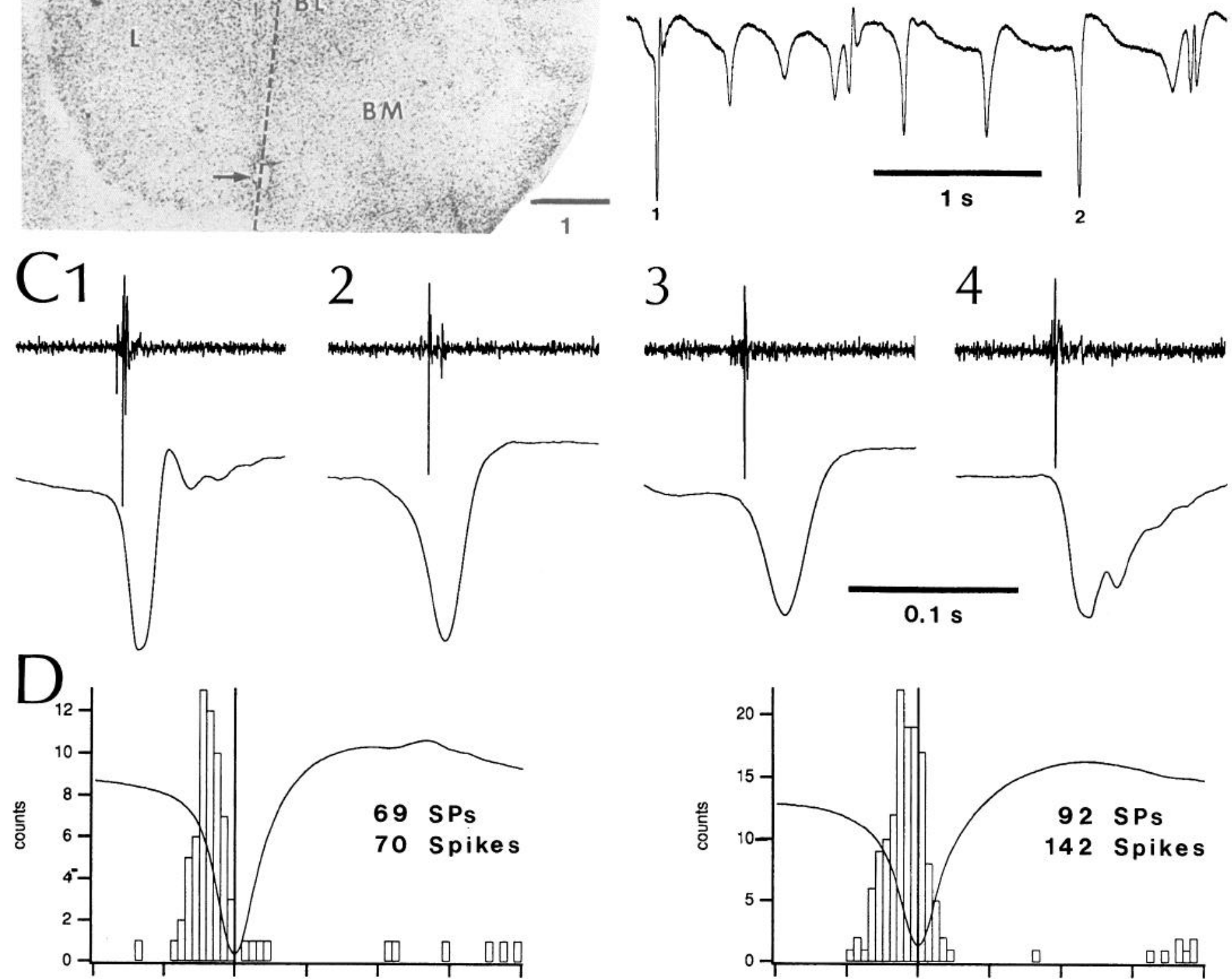

3
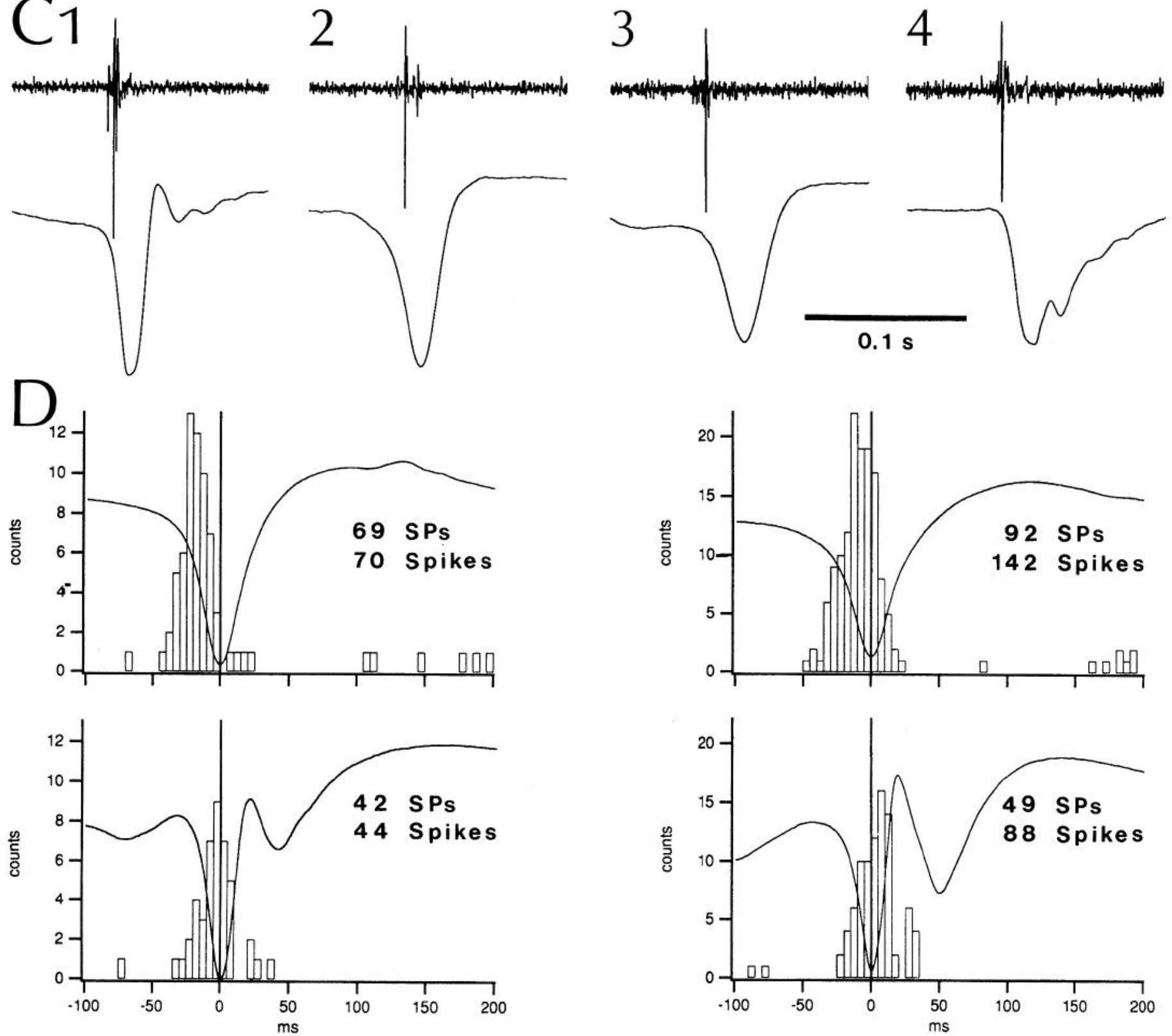

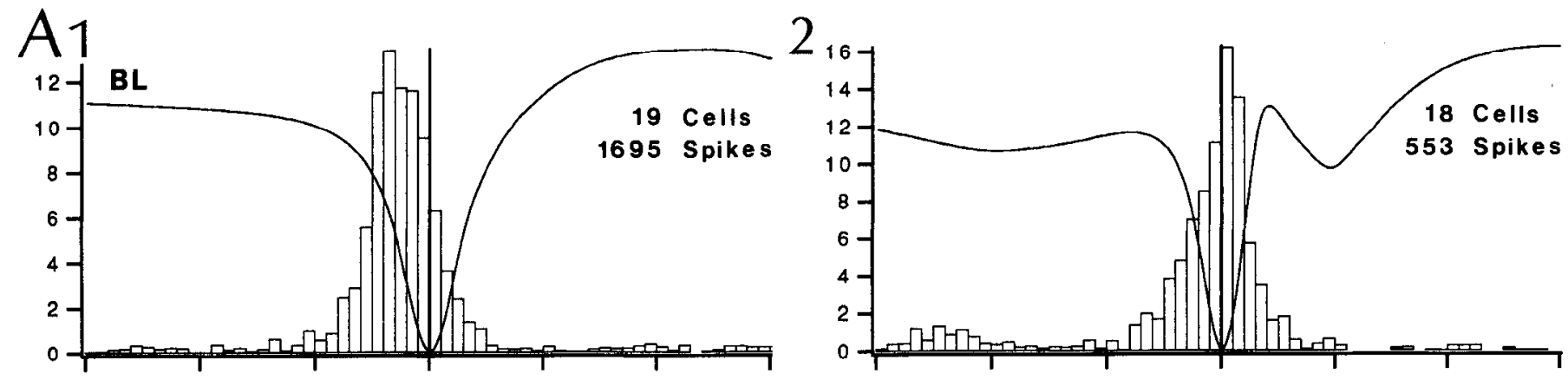

B1
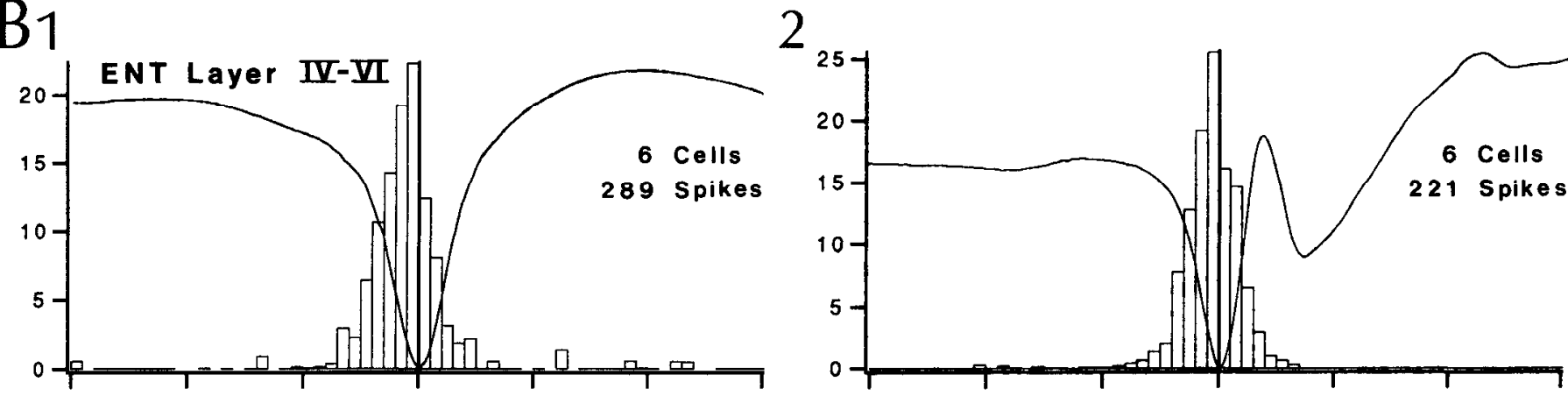

$\mathrm{C}_{1}$

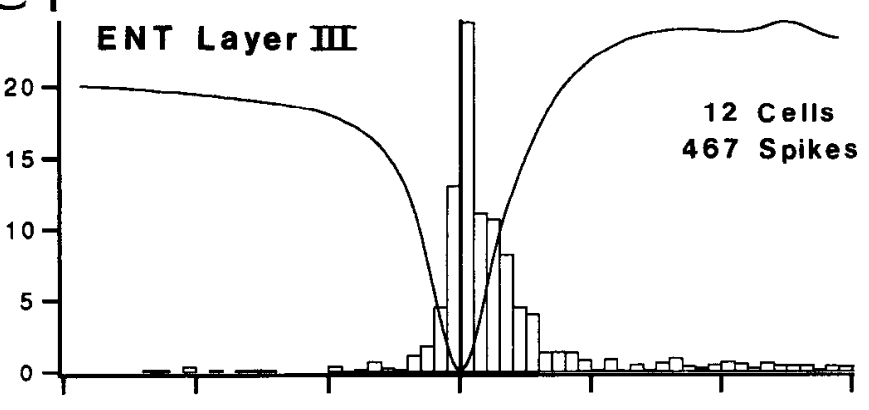

2

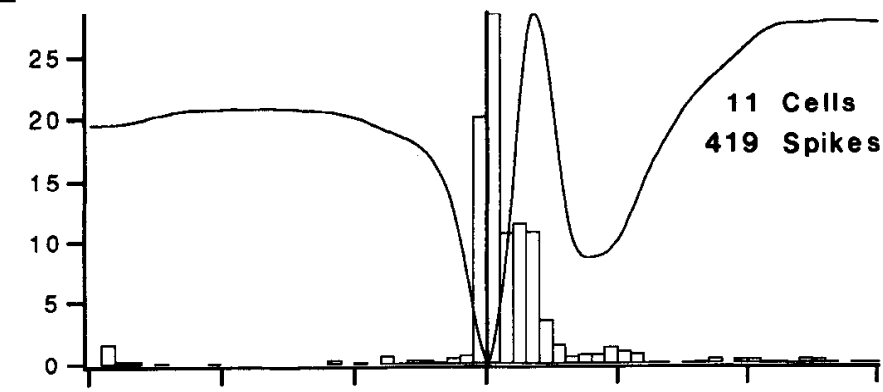

$\mathrm{D}$

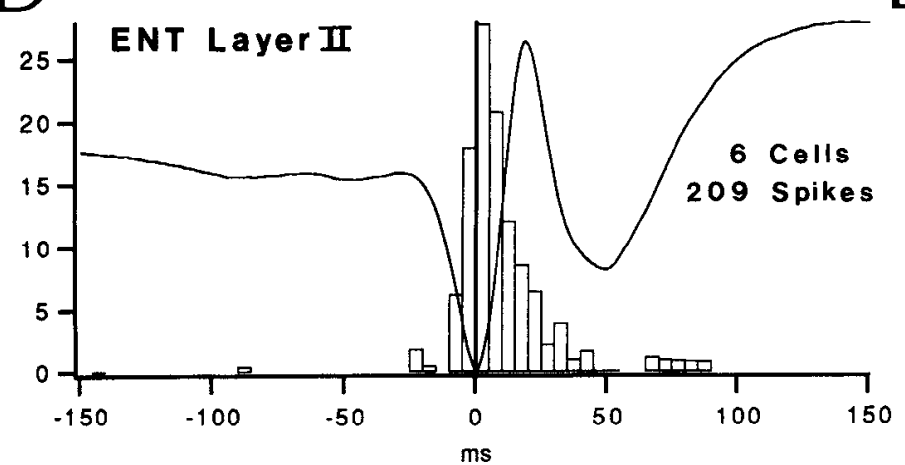

E

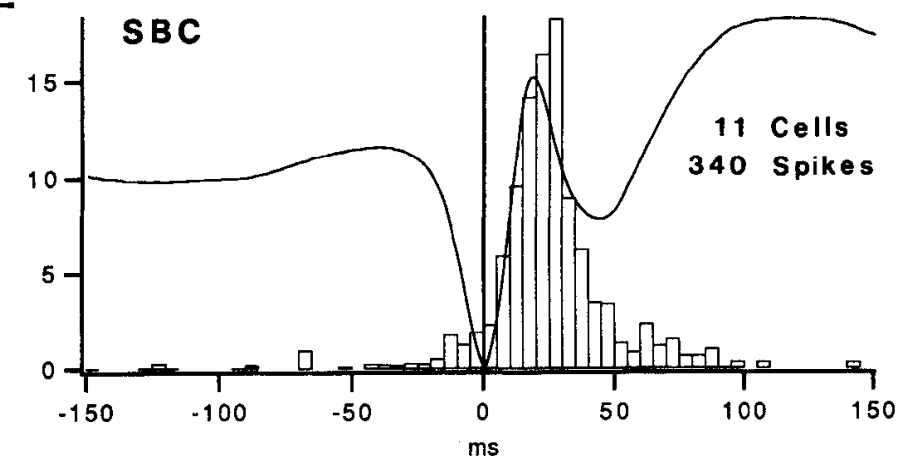

Figure 12. Grouped peri-SP histograms of neuronal discharges. $A$, Neurons of the BL nucleus. $B$, Layers IV-VI ENT neurons. $C$, Layer III ENT neurons. D, Layer II ENT neurons. E, Subicular neurons with selective discharge in relation to complex SPs. With the exception of subicular and layer II ENT neurons, simple ( 1 ) and complex (2) peri-SP histograms are provided for these different types of neurons. Ordinate indicates percentage of spikes per bin. Values for abscissa shown in bottom two histograms.

$\leftarrow$

Figure 11. Activity of BL neurons in relation to simple and complex ENT SPs. A, Histological control showing an electrode track through the BL nucleus. Two electrolytic lesions (arrowhead and arrow) mark the location of the first and last encountered neurons discharging before the negative peak of reference ENT SPs. Calibration bar in millimeters. $B$, SP-related activity of BL neurons (upper trace) recorded at the site marked by an arrowhead in $A$ and simultaneously recorded ENT SPs (lower trace). Unit activity was high-pass filtered at $300 \mathrm{~Hz}$. Numbered SPs in $B$ are illustrated with an expanded time base in CI-2. D:I eft, Peri-SP histograms of neuronal activity for the cell emitting the large-amplitude spikes shown in $B$ and $C$. D:Right, Peri-SP histograms of neuronal discharge for another BL neuron. 

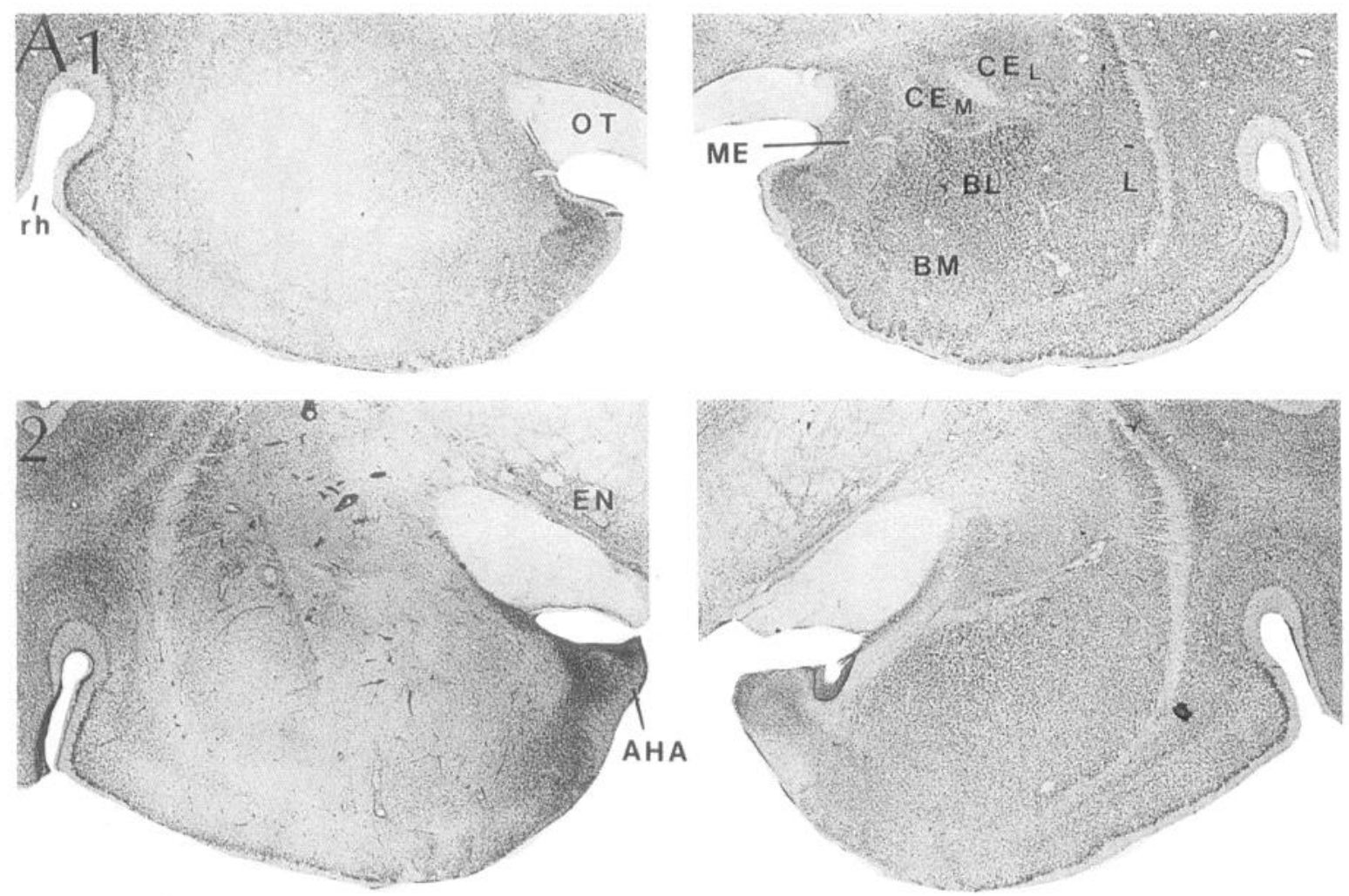

B1
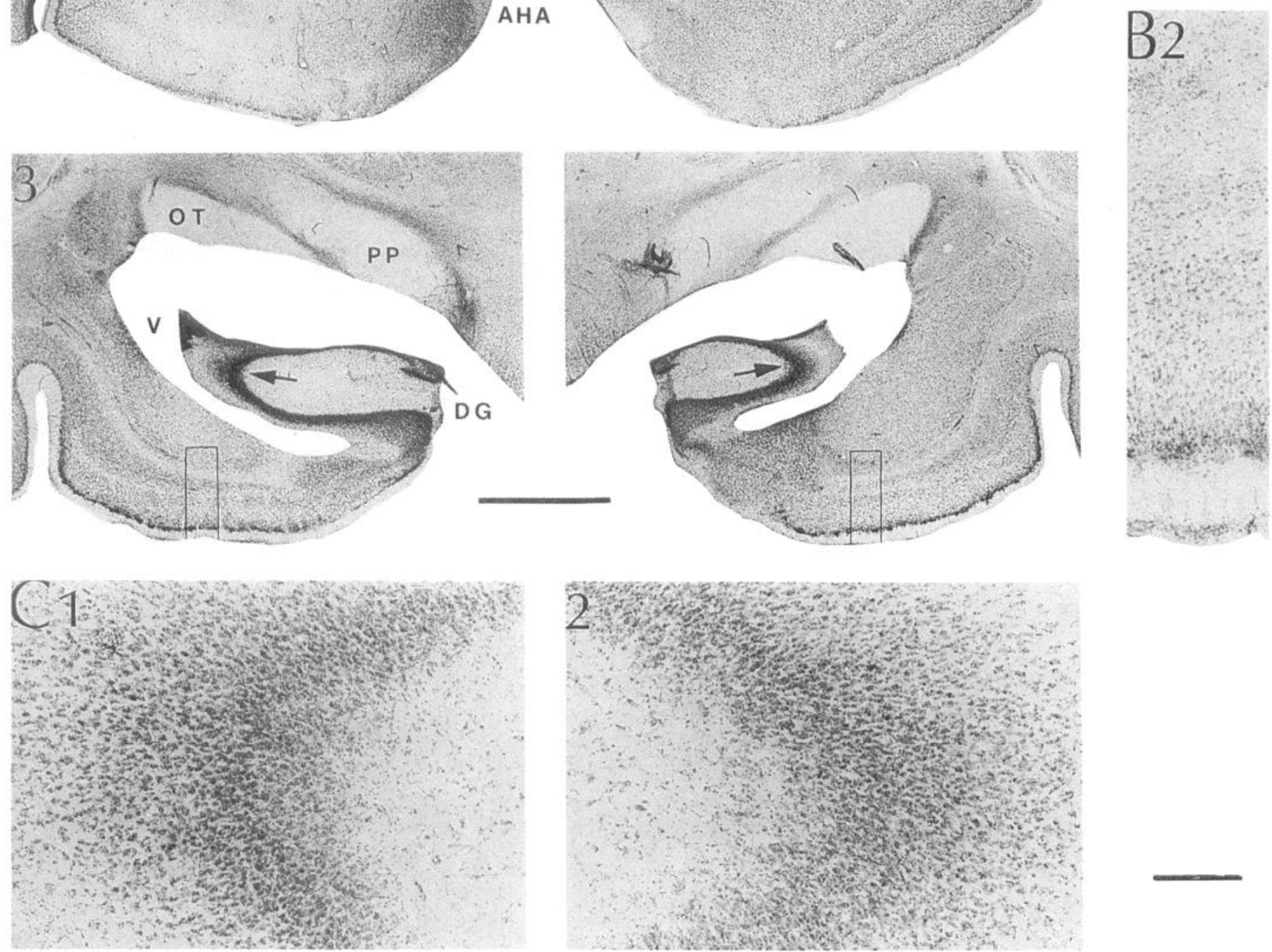

Figure 13. Excitotoxic lesion of the amygdaloid complex. A, Thionin-stained sections of the amygdaloid complex from rostral (1) to caudal (2). The areas closed in black rectangles in $A 3$ are shown at a higher magnification in $B$. The hippocampal sectors indicated by an arrow in $A 3$ are shown at a higher magnification in $C$. In $B$ and $C$, the left and right sides are shown in 1 and 2 , respectively. Scale bars: $A, 3$ mm; $B$ and $C$ (in lower right corner), $2 \mathrm{~mm}$. 


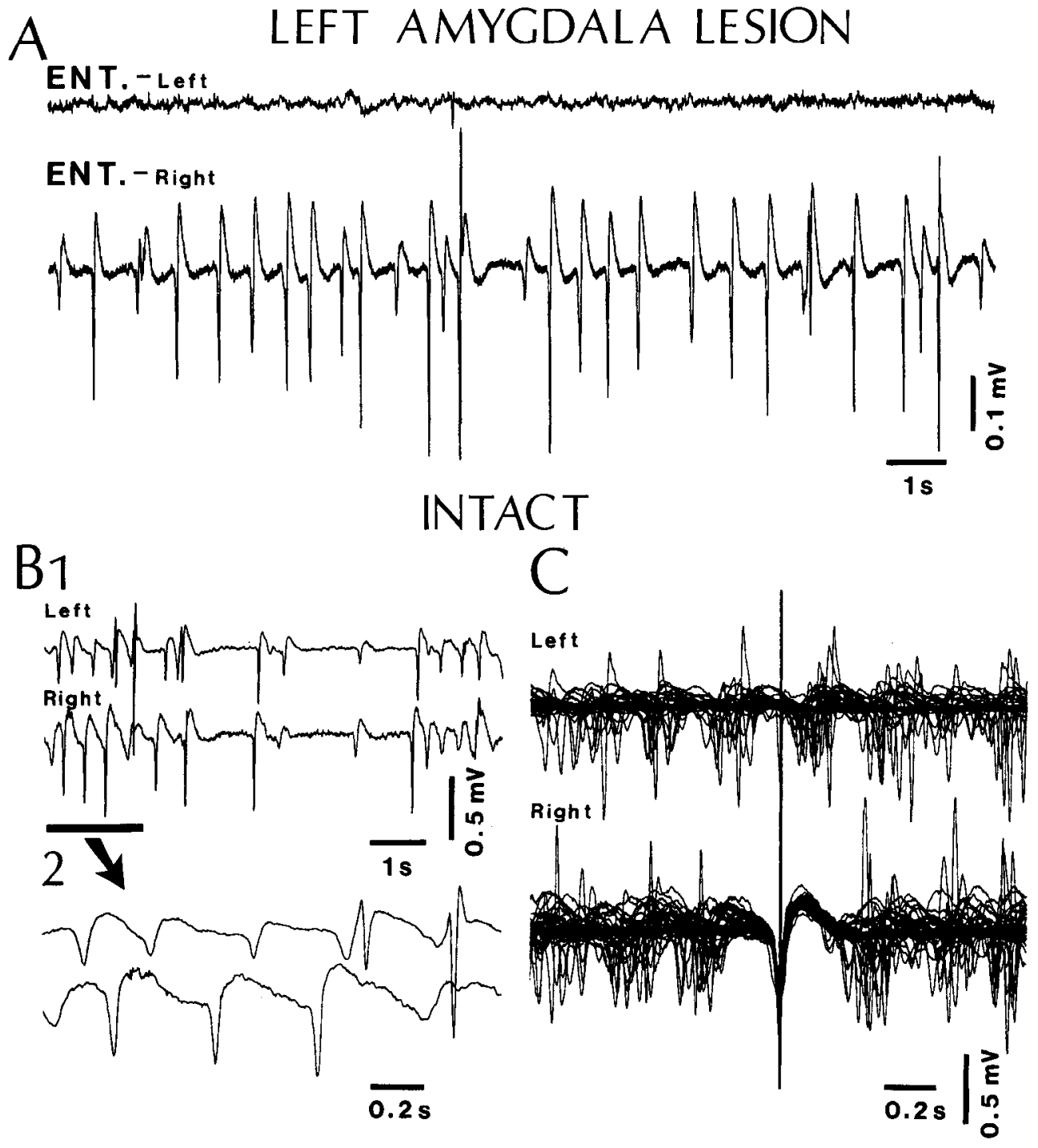

Figure 14. Abolition of ENT SPs by excitotoxic lesion of the amygdaloid complex in barbiturate anesthetized cats $(A), B$ and $C$, Bilateral recording of ENT SPs in an intact barbiturateanesthetized cat. In $C$, the peak of simple ENT SPs recorded on the right was used as a temporal reference to superimposed the $1.6 \mathrm{sec}$ windows of ENT activity. Note that ENT SPs recorded from the left and right side tend to occur in a reciprocal pattern. are consistent with an indirect activation of field CA1 through the trisynaptic path. Furthermore, this interpretation is consistent with the observations of Thomas et al. (1984) who reported that amygdala stimulation evokes field potential responses in the DG that are similar to those evoked by perforant path stimulation except for their longer latency.

In addition, it is possible that monosynaptic ENT inputs from layer III ENT neurons to field CA1 (Steward and Scoville, 1976) contribute to the generation of CAI SPs as Iayer III ENT neurons were on average 16 times more likely to discharge in relation to complex than simple SPs. It is indeed known that monosynaptic entorhinal inputs generate small field potentials in field CAl (Andersen et al., 1966b; Colbert and Levy, 1992). However, it has been reported that direct ENT inputs cannot generate population spikes in field CA1 (Andersen et al., 1966; Colbert and Levy, 1992; Paré and Llinás, 1994). Thus, it appears unlikely that an ENT-CA1-subiculum pathway accounts for the SP-related discharge of subicular neurons.

In the subiculum, two groups of neurons could be distinguished on the basis of their SP-related activities. Most cells (type 1) discharged only in relation to complex ENT SPs (1535 msec after their peak) while others (type 2) discharged in relation to simple and complex ENT SPs. We interpret these findings as evidence of partially overlapping amygdalofugal, ENT, and hippocampal afferents in the subiculum (Krettek and Price, 1977b; Room and Groenewegen, 1986b; Van Groen and Lopes da Silva, 1986; Van Groen et al., 1986). Apparently, some cells are dominated by hippocampal inputs and, as a result, exhibit a delayed discharge in relation to complex SPs (type 1). Because of the long delay between the discharge of superficial ENT neurons and type 1 subicular cells, it appears unlikely that ENT inputs alone could account for the selective and delayed activation of these subicular neurons. The behavior of subicular type 2 cells would be dominated by amygdala and/or deep ENT inputs thus explaining why they discharged with simple and complex ENT SPs.

Surprisingly, the SP-related activation of layer II neurons gave rise to distinct hippocampal events in barbiturate-anesthetized and naturally sleeping cats. During slow-wave sleep, no trace of SP-related ENT inputs could be found beyond the DG. In the molecular layer, dentate SPs appeared as negative potentials that reversed polarity close to the granule cell layer and reached their peak 15-25 msec after complex ENT SPs. Similar events were in the rat DG (Bragin et al., 1994). These potentials, termed dentate EEG spikes, were abolished by ENT lesions and were 
concomitant with a population burst of hilar interneurons (Bragin et al., 1994).

The reason why SP-related ENT synaptic volleys do not activate the trisynaptic path in naturally sleeping animals may reside in the high firing threshold of granule cells. It is indeed known that the firing threshold of dentate granule cells is higher than that of hilar interneurons (Buzsáki and Eidelberg, 1982; Scharfman, 1991). According to this view, the firing of granule cells would be prevented by the activation of hilar neurons having dendrites that extend in the molecular layer (Amaral, 1978; Scharfman, 1991).

\section{Implications for the genesis of hypersynchronous events in the amygdalo-hippocampal network}

The present study constitutes the first demonstration that spontaneous events occurring in the amygdaloid complex are reflected in the activity of related cortices. Furthermore, it suggests that the profuse intranuclear connections of the BL nucleus can lead to the generation of explosive population bursts that can recruit a significant number of ENT and subicular neurons. In normal conditions, propagation of population events to the hippocampus is prevented by a number of inhibitory mechanisms that keep its main input stations silent whereas, in experimental models of temporal lobe epilepsy, these safety mechanisms are abolished or overwhelmed thus leading to reentrant, self-sustained activities in ENT-hippocampal circuits (Paré et al., 1992; Stringer and Lothman, 1992). Considering that functional inactivation of the $\mathrm{BL}$ nucleus prevents the development of convulsive scizures in a model of limbic status epilepticus (White and Price, 1993), future experiments should be directed at evaluating the role of the amygdaloid complex in the development and propagation of epileptic activities.

\section{References}

Alonso A, Klink R (1993) Differential electroresponsiveness of stellate and pyramidal-like cells of medial entorhinal cortex layer II. J Neurophysiol 70:128-143.

Amaral DG (1978) A Golgi study of cell types in the hilar region of the hippocampus in the rat. J Comp Neurol 182:851-914.

Amaral DG, Witter MP (1989) The three-dimensional organization of the hippocampal formation: a review of anatomical data. Neuroscience 31:571-591.

Amaral DG, Price JL, Pitkänen A, Carmichael ST (1992) Anatomical organization of the primate amygdaloid complex. In: The amygdala: neurobiological aspects of emotion, memory, and mental dysfunction (Aggleton JP, ed), pp 1-66. New York: Wiley-Liss.

Andersen P, Holmqvist B, Voorhoeve PE (1966a) Entorhinal activation of dentate granule cells. Acta Physiol Scand 66:448-460.

Andersen P, Holmqvist B, Voorhoeve PE (1966b) Excitatory synapses on hippocampal apical dendrites activated by entorhinal stimulation. Acta Physiol Scand 66:461-472.

Berman AL, Jones EG (1982) The thalamus and basal telencephalon of the cat. Madison: University of Wisconsin.

Bragin A, Jandó G, Nádasdy Z, Buzsáki G (1994) Dentate EEG spikes and associated neuronal population bursts in the hippocampal region of the rat. J Neurophysiol, in press.

Buzsáki G (1986) Hippocampal sharp waves: their origin and significance. Brain Res 398:242-252.

Buzsáki G, Eidelberg E (1982) Direct afferent excitation and long-term potentiation of hippocampal interneurons. J Neurophysiol 48:597607.

Chrobak JJ, Buzsáki G (1994) Selective activation of deep layer (VVI) retrohippocampal cortical neurons during hippocampal sharp waves in the behaving rat. J Neurosci 14:6160-6170.

Colbert CM, Levy WB (1992) Electrophysiological and pharmacological characterization of perforant path synapses in CA1: mediation by glutamate receptors. J Neurophysiol $68: 1-8$.

Colino A, Fernández de Molina A (1986) Electrical activity generated in the subicular complex and entorhinal cortices after electrical stimulation of the lateral and basolateral amygdala of the rat. Neuroscience 19:573-580.

Deadwyler SA, West JR, Cotman CW, Lynch G (1975) Physiological studies of the reciprocal connections between the hippocampus and entorhinal cortex. Exp Neurol 49:35-57.

Derbyshire AJ, Rempel B, Forbes A, Lambert EF (1936) The effects of anesthetics on action potentials in the cerebral cortex of the cat. Am J Physiol 116:577-596.

Dong J, Paré D (1994) Intracellular study of neuronal events related to entorhinal (ENT) sharp waves (SWs) in the amygdaloid complex of cats in vivo. Soc Neurosci Abstr 20:151.5.

Feindel W, Penfield W (1954) Localization of discharge in temporal lobe automatism. Arch Neurol Psychiatry 72:605-630.

Finch DM, Wong EE, Derian EL, Chen XH, Nowlin-Finch NL, Brothers LA (1986) Neurophysiology of limbic system pathways in the rat: projections from the amygdala to the entorhinal cortex. Brain Res 370:273-284

Finch DM, Tan AM, Isokawa-Akesson M (1988) Feedforward inhibition of the rat entorhinal cortex and subicular complex. J Neurosci 8:2213-2226.

Jones RSG (1990a) Intrinsic properties of neurones in layer II of the rat entorhinal cortex in vitro. J Physiol (Lond) 425:86P.

Jones RSG (1990b) Synaptic transmission between layers V-VI and layer II of the rat medial entorhinal cortex in vitro. J Physiol (Lond) 429:47P.

Jones RS (1993) Entorhinal-hippocampal connections: a speculative view of their function. Trends Neurosci 16:58-64.

Jones RSG, Buhl EH (1992) Synaptic and intrinsic responses of morphologically identified basket neurons in layer II of the rat entorhinal cortex in vitro. J Physiol (Lond) 446:257P.

Klink R, Alonso A (1993) Ionic mechanisms for the subthreshold oscillations and differential electroresponsiveness of medial entorhinal cortex layer II neurons. J Neurophysiol 70:144-157.

Köhler C (1986) Intrinsic connections of the retrohippocampal region in the rat brain. II. The medial entorhinal area. J Comp Neurol 246: 149-169.

Köhler C (1988) Intrinsic connections of the retrohippocampal region in the rat brain. III. The lateral entorhinal area. J Comp Neurol 271: 208-228.

Köhler C, Wu J-Y, Chan-Palay V (1985) Neurons and terminals in the retrohippocampal region in the rat's brain identified by anti-gammaaminobutyric acid and anti-glutamic acid decarboxylase immunocytochemistry. Anat Embryol 173:35-44.

Krettek JE, Price JL (1977a) Projections from the amygdaloid complex to the cerebral cortex and thalamus in the rat and cat. J Comp Neurol 172:687-722.

Krettek JE, Price JL (1977b) Projections from the amygdaloid complex and adjacent olfactory structures to the entorhinal cortex and to the subiculum in the rat and cat. J Comp Neurol 172:723-752.

Krettek JE, Price JL (1978) A description of the amygdaloid complex in the rat and cat with observations on intra-amygdaloid axonal connections. J Comp Neurol 178:255-280.

Lavond DG, Kim JJ, Thompson RF (1993) Mammalian brain substrates of aversive classical conditioning. Annu Rev Psychol 44:317342.

Liberson WT, Scoville WB, Dunsmore RH (1951) Stimulation studies of the prefrontal lobe and uncus in man. Electroencephalogr Clin Neurophysiol 7:211-222.

Lorente de Nó R (1933) Studies on the structure of the cerebral cortex. I. The area entorhinalis. J Psychol Neurol 45:381-438.

McDonald AJ (1992) Cell types and intrinsic connections of the amygdala. In: The amygdala: neurobiological aspects of emotion, memory, and mental dysfunction (Aggleton JP, ed), pp 67-96. New York: Wiley-Liss.

McDonald AJ, Augustine JR (1993) Localization of GABA-like immunoreactivity in the monkey amygdala. Neuroscience 52:281-294.

Meunier M, Bachevalier J, Mishkin M, Murray EA (1993) Effects on visual recognition of combined and separate ablations of the entorhinal and perirhinal cortex in rhesus monkeys. J Neurosci 13:54185432.

Nitecka L, Ben-Ari Y (1987) Distribution of GABA-like immunoreactivity in the rat amygdaloid complex. J Comp Neurol 266:45-55.

Paré D, Llinás RR (1994) Non-Lamellar propagation of entorhinal in- 
fluences in the hippocampal formation: multiple electrode recordings in the isolated guinea pig brain in vitro. Hippocampus 4:403-409.

Paré D, Smith Y (1993) Distribution of GABA immunoreactivity in the amygdaloid complex of the cat. Neuroscience 57:1061-1076.

Paré D, Smith Y (1994) GABAergic projection from the intercalated cell masses of the amygdala to the basal forebrain in cats. J Comp Neurol 344:33-49.

Paré D, deCurtis M, Llinás RR (1992) Role of the hippocampal-entorhinal loop in temporal lobe epilepsy: extra- and intracellular study in the isolated guinea pig brain in vitro. J Neurosci 12:1867-1881.

Paré D, Dong J, Gaudreau H (1994) Amygdalo-entorhinal relations and their reflection in the hippocampus. Soc Neurosci Abstr 20:151.4.

Rainnie DG, Asprodini EK, Shinnick GP (1993) Intracellular recordings from morphologically identified neurons of the basolateral amygdala. J Neurophysiol 69:1350-1362.

Ramón y Cajal S (1911) Histologie du système nerveux de l'homme et des vertébrés. Paris: Maloine.

Room P, Groenewegen HJ (1986a) Connections of the parahippocampal cortex. I. Cortical afferents. J Comp Neurol 251:415-450.

Room P, Groenewegen HJ (1986b) Connections of the parahippocampal cortex in the cat. II. Subcortical afferents. J Comp Neurol 251: $451-473$.

Ruth RE, Collier TJ, Routtenberg A (1982) Topography between the entorhinal cortex and the dentate septotemporal axis in rats. I. Medial and intermediate entorhinal projecting cells. J Comp Neurol 209:6978.

Scharfman HE (1991) Dentate hilar cells with dendrites in the molecular layer have lower thresholds for synaptic activation by perforant path than granule cells. J Neurosci 11:1660-1673.

Smith Y, Paré D (1994) Intra-amygdaloid projections of the lateral nucleus in the cat: PHA-L anterograde labeling combined with postembedding GABA and glutamate immunocytochemistry. J Comp Neurol 342:232-248.

Squire LR, Knowlton B, Musen G (1993) The structure and organization of memory. Annu Rev Psychol 44:453-495.

Steriade M, Hobson JA (1976) Neuronal activity during the sleepwaking cycle. Prog Neurobiol 6:155-376.

Steward O, Scoville SA (1976) Cells of origin of entorhinal cortical afferents to the hippocampus and fascia dentata of the rat. J Comp Neurol 169:347-370.

Stringer JL, Lothman EW (1992) Bilateral maximal dentate activation is critical for the appearance of an afterdischarge in the dentate gyrus. Neuroscience 46:309-314.

Suzuki A, Zola-Morgan S, Squire LR, Amaral DG (1993) Lesions of the perirhinal and parahippocampal cortices in the monkey produce long-lasting menory impairment in the visual and tactual modalities. J Neurosci 13:2430-2451.

Suzuki SS, Smith GK (1987) Spontaneous EEG spikes in the normal hippocampus. I. Behavioral correlates, laminar profiles and bilateral synchrony. Electroencephalogr Clin Neurophysiol 67:348-359.

Thomas SR, Assaf SY, Iversen SD (1984) Amygdaloid complex modulates neurotransmission from the entorhinal cortex to the dentate gyrus of the rat. Brain Res 307:363-365.

Van Groen T, Lopes Da Silva FH (1985) Septotemporal distribution of entorhinal projections to the hippocampus in the cat: electrophysiological evidence. J Comp Neurol 238:1-9.

Van Groen T, Lopes Da Silva FH (1986) The organization of the reciprocal connections between the subiculum and the entorhinal cortex in the cat. II. An electrophysiological study. J Comp Neurol 251: 111120.

Van Groen T, van Haren FJ, Witter MP, Groenewegen HJ (1986) The organization of the reciprocal connections between the subiculum and the entorhinal cortex in the cat. I. A neuroanatomical tracing study. J Comp Neurol 250:485-497.

Washburn MS, Moises HC (1992) Electrophysiological and morphological properties of rat basolateral amygdaloid neurons in vitro. J Neurosci 12:4066-4079.

White LE, Price JL (1993) The functional anatomy of limbic status epilepticus in the rat. II. The effects of focal deactivation. J Neurosci 13:4810-4830.

Witter MP, Groenewegen HJ (1984) Laminar origin and septotemporal distribution of entorhinal and perirhinal projections to the hippocampus in the cat. J Comp Neurol 224:371-385.

Witter MP, Ronm P, Groenewegen HI, I ohman AHM (1986) Connections of the parahippocampal cortex in the cat. V. Intrinsic connections; Comments on input/output connections with the hippocampus. J Comp Neurol 252:78-94.

Witter MP, Groenewegen HJ, Lopes da Silva FH, Lohman AHM (1989) Functional organization of the extrinsic and intrinsic circuitry of the parahippocampal region. Prog Neurobiol 33:161-253.

Zola MS, Squire LR, Clower RP, Rempel NL (1993) Damage to the perirhinal cortex exacerbates memory impairment following lesions to the hippocampal formation. J Neurosci 13:251-265. 